\title{
Heat and drought adaptive QTL in a wheat population designed to minimize confounding agronomic effects
}

\author{
R. Suzuky Pinto $\cdot$ Matthew P. Reynolds • \\ Ky L. Mathews • C. Lynne McIntyre • \\ Juan-Jose Olivares-Villegas $\cdot$ Scott C. Chapman
}

Received: 30 November 2009/Accepted: 28 April 2010/Published online: 4 June 2010

(C) The Author(s) 2010. This article is published with open access at Springerlink.com

\begin{abstract}
A restricted range in height and phenology of the elite Seri/Babax recombinant inbred line (RIL) population makes it ideal for physiological and genetic studies. Previous research has shown differential expression for yield under water deficit associated with canopy temperature (CT). In the current study, 167 RILs plus parents were phenotyped under drought (DRT), hot irrigated (HOT), and temperate irrigated (IRR) environments to identify the genomic regions associated with stress-adaptive traits. In total, 104 QTL were identified across a combination of 115 traits $\times 3$ environments $\times 2$ years, of which 14,16 , and 10 QTL were associated exclusively with DRT, HOT, and IRR, respectively. Six genomic regions were related to a large number of traits, namely $1 \mathrm{~B}-\mathrm{a}, 2 \mathrm{~B}-\mathrm{a}, 3 \mathrm{~B}-\mathrm{b}, 4 \mathrm{~A}-\mathrm{a}$, 4A-b, and 5A-a. A yield QTL located on 4A-a explained 27 and $17 \%$ of variation under drought and heat stress, respectively. At the same location, a QTL explained 28\% of the variation in CT under heat, while $14 \%$ of CT variation under drought was explained by a QTL on 3B-b. The
\end{abstract}

Communicated by J. Snape.

Electronic supplementary material The online version of this article (doi:10.1007/s00122-010-1351-4) contains supplementary material, which is available to authorized users.

\author{
R. S. Pinto · M. P. Reynolds $(\bowtie)$ \\ CIMMYT, Int. Apdo. Postal 6-641, \\ 06600 Mexico DF, Mexico \\ e-mail: m.reynolds@cgiar.org \\ R. S. Pinto \\ e-mail: suzukypinto@yahoo.com.mx \\ K. L. Mathews - C. L. McIntyre - J.-J. Olivares-Villegas · \\ S. C. Chapman \\ CSIRO Plant Industry, Queensland Bioscience Precinct, \\ St. Lucia, QLD 4067, Australia
}

T1BL.1RS (rye) translocation donated by the Seri parent was associated with decreased yield in this population. There was no co-location of consistent yield and phenology or height-related QTL, highlighting the utility of using a population with a restricted range in anthesis to facilitate QTL studies. Common QTL for drought and heat stress traits were identified on 1B-a, 2B-a, 3B-b, 4A-a, 4B-b, and 7A-a confirming their generic value across stresses. Yield QTL were shown to be associated with components of other traits, supporting the prospects for dissecting crop performance into its physiological and genetic components in order to facilitate a more strategic approach to breeding.

\section{Introduction}

With few exceptions (Richards 2006), breeding for drought adaptation has been largely empirical or based on drought escape through manipulation of development, so that sensitive development stages do not coincide with the greatest risk and effect of stress (Ludlow and Muchow 1990). Although conventional breeding has had substantial impact in marginal wheat growing environments (Lantican et al. 2003), future genetic gains will require a more systematic use of physiological and genetic approaches, facilitated by the rapid increase in genome knowledge and understanding. An example of physiological application is how the ability to use water more slowly and efficiently has improved performance of wheat cultivars under late-season drought conditions of Australia, via the crossing and selecting for high transpiration efficiency (TE) (Condon et al. 2004). In situations where water is available in deep soil profiles, the ability to extract it under water-limited conditions has been identified as the principal mechanism for drought adaptation as shown by a robust association of canopy temperature 
(CT) with wheat yields (Olivares-Villegas et al. 2007). Traits such as these that are rapid and integrative in nature are increasingly recognized not only as useful selection tools in breeding (Araus et al. 2008) but as valuable screens for high throughput phenotyping of mapping populations (Montes et al. 2007; Olivares-Villegas et al. 2008). In addition to CT, several other physiological traits can be either rapidly phenotyped and/or informative about how adaptation to drought and heat can arise. Normalized difference vegetative index (NDVI) is an integrated measure of both ground cover (leaf area) and the nitrogen content of the canopy. Both NDVI and chlorophyll meters provide an indirect estimation of leaf health for photosynthesis as associated with leaf nitrogen content and early senescence (Araus et al. 2008). Given similar canopy leaf area, the maintenance of healthy green leaves under stress can be interpreted as stress tolerance for either drought or heat conditions (Olivares-Villegas et al. 2007; Tao et al. 2000).

Mapping quantitative trait loci (QTL) in bi-parental populations allows the detection of chromosome segments controlling traits of agronomic interest with the opportunity to dissect complex traits (those traits that integrate the effect of a number of factors occurring during the crop cycle) into component loci (Marza et al. 2006). Detected regions can be used in breeding and pre-breeding to increase its efficiency through marker-assisted selection (Campbell et al. 2003). In both maize and soybean, new cultivars have been released to markets following the rapid recombination of favorable yield QTL through marker-assisted recurrent selection strategies based on multi-environment assessments of bi-parental populations, e.g. Eathington et al. (2007). While effective in generally favorable production environments, this approach is potentially confounded for traits under stress due to the existence of interactions of multiple physiological processes and environmental influences over the period of the crop cycle.

In recent years, large numbers of QTL have been reported in diverse cereals for a range of agronomic traits: for example, in barley, QTL have been reported for yield under drought environments (Comadran et al. 2008; Talamè et al. 2004), and in wheat, QTL for seed size, seed shape (Breseghello and Sorrells 2007), plant height, maturity, and grain yield (Kato et al. 2000; Kuchel et al. 2007; Marza et al. 2006; McCartney et al. 2005; Snape et al. 2007). However, relatively few studies have examined QTL for physiological traits and their co-location with effects on crop yield and quality. Exceptions are for concentration of water soluble carbohydrates (WSC) and carbon isotope discrimination (CID) (Rebetzke et al. 2008a; Rebetzke et al. 2008b; Yang et al. 2007) although these studies were partially confounded by variation in flowering time and height in the populations. Public research on QTL in cereals has often utilized greatly contrasting parents, including land- races. However, QTL associated with stress responses in such populations may be confounded by other differences, or have already been fixed in elite breeding programs.

In this paper, the population studied is an elite cross (Seri/Babax), and does not segregate for known major height (Rht genes), vernalization (Vrn1:Vrn-Alc, Vrn-B1, and $V r n-D l$ ) or photoperiod response genes (Ppdl). Consequently, the lines have shown low variation for both flowering time and height (Olivares-Villegas et al. 2007). This potentially increases the opportunity to identify QTL that may otherwise be masked by the confounding effects of crop development. By phenotyping in both drought and hot/irrigated environments, the study aimed to confirm the existence of common genetic bases between adaptation to moisture and heat stress that have been indicated by physiological studies in the same environments (Reynolds et al. 2007). Specific objectives of this study were: (1) to identify QTL associated with agronomic and physiological traits in six environments encompassing drought, heat, and well-irrigated conditions; (2) to demonstrate the value of using progeny from an elite by elite cross expressing a restricted range of height and phenology for improving the QTL detection; (3) to determine genomic regions consistently associated with adaptation to both drought and hot, irrigated environments; and (4) to interpret 'genetic dissection' of yield in terms of QTL simultaneously associated with yield, yield components, and stress-adaptive traits contributing to performance.

\section{Materials and methods}

\section{Plant material and field trials}

A recombinant inbred line (RIL) population consisting of 167 sister lines was studied in managed environments in north-west Mexico. The population was derived from a reciprocal cross between the related elite lines: semi-dwarf spring wheat variety Seri M82 from the "Veery" cross (KVZ/BUHO//KAL/BB) and a fixed line (Babax) derived from the "Babax" cross (BOW/NAC//VEE/3/BJY/COC). Seri M82 carries the T1BL.1RS (rye) translocation, and is characterized by moderate tolerance to drought conditions and high yield potential. The Babax parental line has a coefficient of parentage of 0.3316 with Seri M82 (Mathews et al. 2008). It is a sister line of the elite variety Baviacora M92 (recognized for drought tolerance and also has a high yield potential), but was selected so as not to carry the T1BL.1RS rye translocation that is in present in Baviacora M92 and Seri M82 (see Mathews et al. 2008 for details). The parental lines, termed here as Seri and Babax, have been screened for known phenology alleles, and both parents have the photoperiod-insensitive allele at $P p d-\mathrm{D} 1$, as 
well as spring-type alleles for at least two vernalization (Vrn-B1 and Vrn-D1) loci (K Cane, Department of Primary Industries, Victoria, Australia). Hence, the population is characterized by its narrow range of height and flowering time (ca. 10-15 days), and was developed primarily for genetic mapping and screening for the physiological basis of stress tolerance in drought and heat environments (Olivares-Villegas et al. 2007).

Six field trials were sown between 2002 and 2006, under three different environments: two under terminal drought (D02 and D05; total crop water supply $\leq 300 \mathrm{~mm}$ ); two under high environmental temperatures due to a delayed planting date, but irrigated throughout the crop cycle (H05 and $\mathrm{H} 06$; average $T_{\max }>32^{\circ} \mathrm{C}$; total crop water supply $>700 \mathrm{~mm}$ ); and two controls under well-irrigated conditions (I02 and I06; total crop water supply $>700 \mathrm{~mm}$ ). The trial naming protocol was: letters $\mathrm{D}, \mathrm{H}$, and $\mathrm{I}$ to indicate drought (DRT), heat (HOT) or irrigated (IRR) conditions, and the two-digit numbers indicate the year of harvest. During the two DRT cycles, available water (including rainfall) was estimated at ca. 195 and $260 \mathrm{~mm}$ for D02 and D06, respectively. For HOT and IRR treatments, irrigation was applied when approximately 50\% of available soil moisture (in the $0-1 \mathrm{~m}$ profile) was depleted, so water was assumed not to limit growth. Available soil water for the DRT trials was estimated from gravimetric sampling of neighboring plots after irrigation. All trials were sown in two-replicate alpha-lattice designs in the Yaqui Valley, Mexico at CIMMYT's Obregon Experimental Station, located in north-western Mexico $\left(27^{\circ} 25^{\prime} \mathrm{N} 109^{\circ} 54^{\prime} \mathrm{W}, 38 \mathrm{~m}\right.$ above sea level). The site is a high radiation, irrigated environment (Table 1). The soil is a Typic Calciorthid, low in organic matter $(0.76 \%)$ and slightly alkaline $(\mathrm{pH} 7.7)$ with a plant-available water holding capacity of about $200 \mathrm{~mm}$. Soil analyses conducted previously at various profiles did neither indicate problems associated with mineral deficiencies or toxicities, nor salinity problems (Olivares-Villegas et al. 2007). Appropriate fertilization, weed, disease, and pest control were implemented to minimize other yield limitations. Plots comprised two $80-\mathrm{cm}$ raised beds spaced at $60 \mathrm{~cm}$ between centers and comprising two rows per bed. There were slight variations in plot lengths (l) and seeding rate $(d)$ : in D02 $l=6 \mathrm{~m}, d=12.5 \mathrm{~g} \mathrm{~m}^{-2}$; in D05 $l=4.5 \mathrm{~m}, d=12.5 \mathrm{~g} \mathrm{~m}^{-2} ; \mathrm{H} 05 l=4 \mathrm{~m}, d=11.7 \mathrm{~g}$ $\mathrm{m}^{-2} ; \quad \mathrm{H} 06 l=4 \mathrm{~m}, d=15.6 \mathrm{~g} \mathrm{~m}^{-2} ; \quad \mathrm{I} 02 l=5 \mathrm{~m}, d=$ $15 \mathrm{~g} \mathrm{~m}^{-2}$; in $\mathrm{I} 06 \mathrm{l}=5 \mathrm{~m} d=10 \mathrm{~g} \mathrm{~m}^{-2}$. Olivares-Villegas et al. (2007) described the 2002 trials in detail.

Field methods and trait calculations

The recorded traits were classified into three groups: (1) agronomic traits, (2) phenological traits and height, and (3) physiological traits. Agronomic traits included final

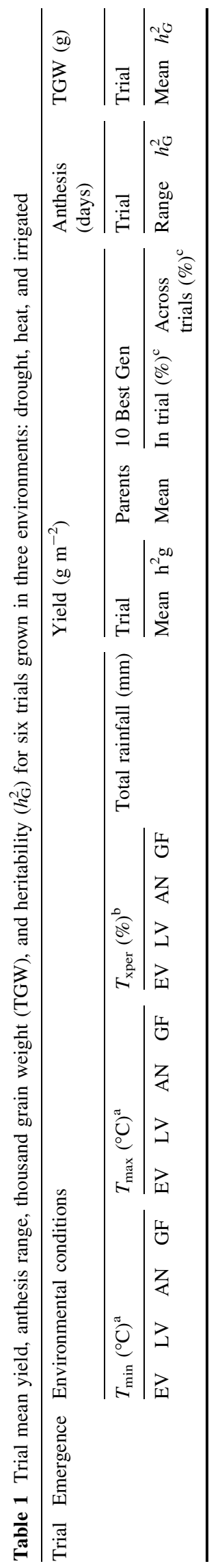


grain yield (yield, $\mathrm{g} \mathrm{m}^{-2}$ ), grain number $\left(\mathrm{GM}^{-2}\right)$, thousand grain weight (TGW, g), and kernel weight index (KWI). According to the population average grain size to calculate KWI, the harvested grains from each line were sampled, and using a $19 \times 3 \mathrm{~mm}$ sieve (to avoid a group containing only broken grains and rubbish), the sample was classified into two groups (large grains and small grains). KWI was calculated as:

$$
\left(\frac{\mathrm{Lg}}{\mathrm{Lg}+\mathrm{Sg}}\right) \times\left(\frac{\mathrm{TGW}(\mathrm{I})_{\mathrm{ave}}}{\mathrm{TGW}(\mathrm{I})_{\text {line }}}\right),
$$

where $\mathrm{Lg}$ is the mass of large grains in the sample, $\mathrm{Sg}$ is the mass of small grains in the sample, TGW(I) $)_{\text {ave }}$ is the average thousand grain weight for both irrigated trials (I02 and I06), and TGW(I)line is the average thousand grain weight for individual lines in the irrigated trials (a larger KWI indicating an increased proportion of larger grains normalized to irrigated conditions). Anthesis (ANTH), maturity (MAT), and height were included in the group of agronomic and morphological traits. ANTH was recorded as the number of days for $50 \%$ of plants to exhibit burst anthers, and MAT was recorded when $50 \%$ of the spikes in a plot showed total loss of green color (MAT). Physiological traits included canopy temperature in the vegetative stage $\left(\mathrm{CTv},{ }^{\circ} \mathrm{C}\right)$, canopy temperature in the grainfill stage $\left(\mathrm{CTg},{ }^{\circ} \mathrm{C}\right)$, normalized difference vegetative index in the vegetative stage (NDVIv), normalized difference vegetative index in the grainfill stage (NDVIg), chlorophyll content in the grainfill stage (CHLg), and water soluble carbohydrate content of stems at anthesis (WSC, \%). Canopy temperature was measured using a portable infrared thermometer (Mikron M90 series) twice in the day if possible, in the morning (10:00-12:00 h) and in the afternoon (12:00-15:00) of fine windless days during vegetative (CTv) and grainfill (CTg) stages (Olivares-Villegas et al. 2007). CT was recorded on an average of four occasions during each growth stage by pointing to the canopy from the edge of the plot for approximately $5 \mathrm{~s}$ and located with the sun behind the observer, avoiding shadows. Each CT measurement (stage $\times$ by time of day) was statistically modeled and QTL mapped individually. Adjusted means were also averaged for each growth stage, and one data point for CTv and one for CTg was reported. NDVI was obtained using a GreenSeeker sensor (Optical Sensor Unit, 2002 Ntech Industries, Inc., Ukiah, CA, USA) with repeated measurements during the vegetative (NDVIv) and grainfill (NDVIg) stages (Araus et al. 2008; Marti et al. 2007). The instrument records the reflectance in one bed per plot at speeds of 10-20 times/plot; all zero values resulting from measuring the soil were deleted, and the average per plot was reported; the statistical analysis was also done individually for each measurement. CHLg was recorded using a portable chlorophyll meter (SPAD-502
Minolta, Spectrum Technologies Inc., Plainfield, IL, USA). During the grainfilling stage, six leaves were sampled per plot, and the average was reported; WSC was measured by sampling and drying 12 stems cut between 6 and 8 days after $50 \%$ anthesis for each plot, and estimating the percentage with Near-infrared Reflectance Spectroscopy (Foss NIRSystems mod. 6500, Uruguay) previously calibrated against chemical measurement (Ruuska et al. 2006). For logistical reasons, not all traits were collected in all experiments: in D02 observations were missing for KWI and WSC; in D05 CTv; in I02 KWI, CTv, NDVIv, NDVIg, and WSC. A detailed description of the traits measured in year 2002 can be found in Olivares-Villegas et al. (2007).

Statistical analysis of the traits data

Adjusted means (Best Linear Unbiased Estimates; BLUEs) were calculated from a spatial model using the REML procedure in Genstat Discovery Edition 3 (http://www.vsni. co.uk/). Although the Seri/Babax population has a narrow range of anthesis dates, in order to detect QTL independent from phenology, anthesis was tested as a covariate for all the traits resulting significant in the major of the physiological traits and also KWI but generally not significant for yield and yield components. The anthesis date was included as a covariate in the models of all the physiological traits plus KWI under all the environments $\times$ year combinations. To obtain variance components, first, the best spatial model was determined individually for each trait $x$ environment $\times$ year combination, assuming random genotype effects and an autoregressive process of order 1 in both the row and columns directions (AR1 × AR1). The models included the experimental design factors for an $\alpha$-lattice design: replicates and replicates $x$ subblock. Global spatial trends in the row and column directions and extraneous spatial effects, like the direction of recording data, were also modeled following Gilmour et al. (1997). Genotype was then fitted as a fixed effect using these best spatial models to obtain the BLUEs and weights (Smith et al. 2001), which were used in the subsequent QTL analysis. A multiple linear regression was performed for yield, TGW, and $\mathrm{GM}^{-2}$ using Statgraphics Plus V4.0. Genetic correlations $\left(r_{\mathrm{g} i j}\right)$ between traits $i$ and $j$ were calculated using the genotypic variance and covariance component estimates:

$r_{\mathrm{g} i j}=\frac{\sigma_{\mathrm{G} i j}}{\sigma_{\mathrm{G}} \sigma_{\mathrm{G} j}}$,

where $\sigma_{G i j}$ is the genotypic covariance between traits $i$ and $j$, and $\sigma_{\mathrm{G} i}$ and $\sigma_{\mathrm{G} j}$ are the estimated genotypic standard deviations for trait $i$ and $j$, respectively (Holland 2006).

For each trait, in each trial, the broad sense heritability was calculated based on Falconer (1981) and modified for spatial adjustments according to Cullis et al. (2006) and 
Oakey et al. (2006). The components of the following formula were derived from the random genotype effects model. The formula is:

$h_{\mathrm{G}}^{2}=1-\frac{\text { avesed }^{2}}{2 \mathrm{Vg}}$,

where avesed is the average standard error of the difference for the set of BLUPs and Vg is the genetic variance for the trait.

QTL mapping of the agronomic, phenological, and physiological traits

Prior to this study, a molecular map was constructed from 74 SSR (Single Sequence Repeat), 249 AFLP (Amplified Fragment Length Polymorphisms), and 264 DArT (Diversity Array Technology) markers (McIntyre et al. 2010). The final map used 401 markers to define 29 linkage groups with only chromosomes $3 \mathrm{D}$ and $7 \mathrm{D}$ missing (see Mathews et al. 2008 for further details on the map construction). Prior to QTL analysis, variance analyses were performed using Genstat Discovery Edition 3 to determine the existence of significant genetic variability between RILs. Those traits without a significant genotypic variance were not included in the QTL mapping. Composite interval mapping (CIM) was undertaken using Windows QTL Cartographer v2.0 (Wang et al. 2007) with the program's default values: a genome $10.0 \mathrm{cM}$ wide, significance level of 0.05 , and a walk speed of $2 \mathrm{cM}$ in forward regression with five cofactor markers. The BLUEs generated from the spatial analyses were used and the LOD (logarithm of odds ratio) scores obtained. A QTL was declared if two or more close markers $(\leq 30 \mathrm{cM})$ were linked to a locus of significant LOD. Significant profiles were determined if the LOD score of the locus was greater than 2 (McIntyre et al. 2010). Other authors have used LOD as low as 2.5 (Sun et al. 2008; Yang et al. 2007), but the current study has an exploratory focus and hence indicative QTL signals (2-2.5) were not excluded. Significant QTL (LOD > 2) were further classified according to their appearance in more than one environment as follows: (a) repeatable QTL when it appeared only in both years of any environment; (b) stress QTL when it appeared in both years of one stress environment and at least 1 year of the other stressed environment; and (c) robust when the QTL was detected in at least 1 year of irrigated plus 2 years of an stressed environment, or vice versa. Weaker effects that appeared only in 1 year of any environment were classified as suggestive QTL; isolated LOD significant signals in only one marker but not in nearby markers $(\leq 30 \mathrm{cM})$ were not considered as a QTL even when it appeared in more than one environment.

\section{Results}

Weather conditions under which the six trials were undertaken

Minimum and maximum temperature and total rainfall in the crop were recorded for each trial (Table 1). The temperatures were summarized into four crop stages: emergence to vegetative (EV), late vegetative (LV), anthesis (AN), and grainfill (GF) (Table 1). For IRR treatments, conditions were typical of a high radiation, irrigated, spring wheat environment with solar radiation and temperatures increasing from March through grain-filling (Table 1). The rainfall for all six trials was negligible (Table 1). Consequently, the DRT trials resulted in gradually intensifying moisture stress levels as water from seeding irrigations was depleted. For the late sown trials (HOT), gradually increasing above-optimal temperatures were experienced throughout the cycle (Table 1). Maximum temperatures in all stages were recorded in the HOT trials, as expected. In both years of the HOT environment, all the stages but early vegetative, experienced maximum temperatures greater than $30^{\circ} \mathrm{C}$ on more than $90 \%$ of days.

\section{Agronomic and physiological trait screening}

Mean, minimum, maximum, and standard deviation of the agronomic and physiological traits in all six trials are presented in Table 2. Yield under DRT and HOT were reduced, on average, by 50 and $59 \%$, respectively, compared with the IRR environment. The average IRR yield was approximately $620 \mathrm{~g} \mathrm{~m}^{-2}$ with the best lines yielding almost $800 \mathrm{~g} \mathrm{~m}^{-2}$ in the best year and the worst lines $475 \mathrm{~g} \mathrm{~m}^{-2}$ in the worst year (data not shown). Compared with the IRR treatments, stress treatments generally reduced grain number $\left(\mathrm{GM}^{-2}\right)$ more than grain weight (TGW), i.e. in D02, the $\mathrm{GM}^{-2}$ reduction was almost $51 \%$ while TGW was reduced by $21 \%$. Kernel weight index (KWI) values were lower in the stressed environments, indicating a greater proportion of small and shriveled grains (Table 2).

The growth cycle averaged 126 days from crop emergence to physiological maturity under IRR conditions, but was reduced, on average, by 12 days (10\%) under DRT and 45 days (40\%) under HOT conditions (Table 2). The relative duration of grainfilling (MAT-ANTH)/MAT, as a fraction of crop cycle length, was $0.29,0.26$, and 0.30 for DRT, HOT, and IRR, respectively. Mean canopy temperatures varied predictably according to air temperature and soil moisture while the range among genotypes within trials was $1-4^{\circ} \mathrm{C}$ (from the coolest to the warmest genotypes), with the range typically greater under stress compared with IRR. The spectral index NDVIv measured in the vegetative 


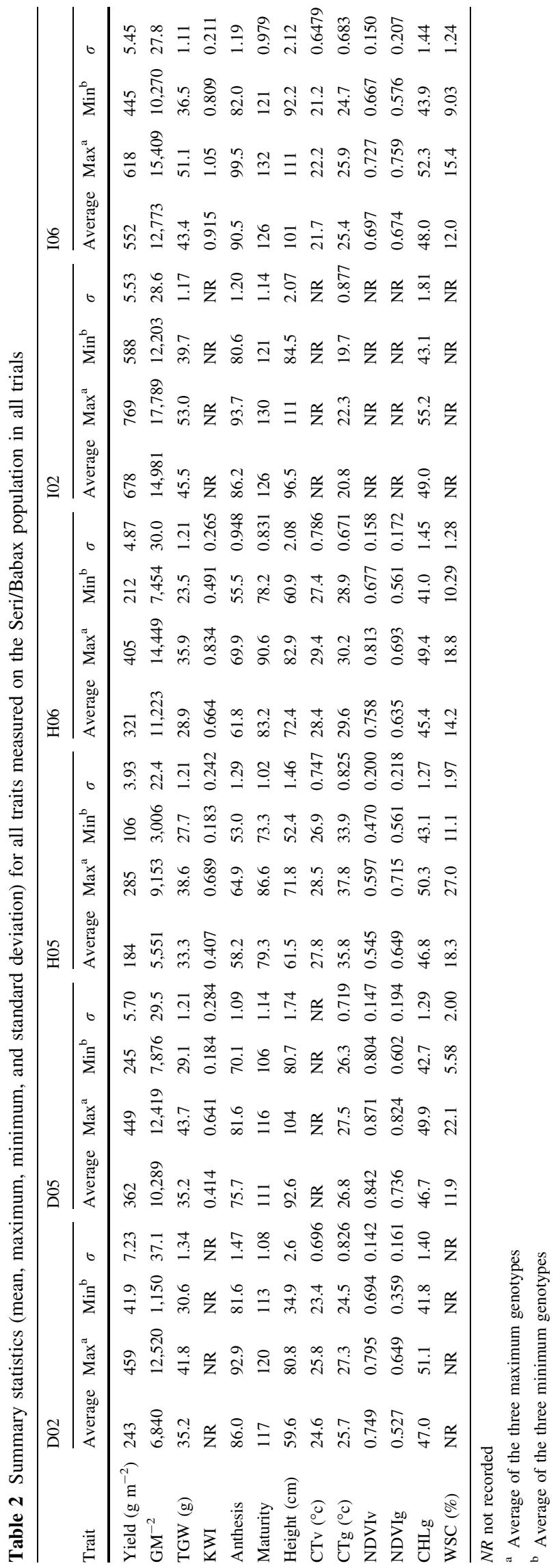

stages was generally consistent with high levels of ground cover for all sites and genotypes, with the exception of the HOT site in 2005, where incomplete ground cover resulted in low values. Stem water soluble carbohydrate (WSC) data were not collected in all environments, but the mean values were greatest in the HOT environments, and genetic variation was substantial in all environments.

The lowest yielding trials were H05 and D02 (Table 1). However, the ten best genotypes within these trials recorded 73\% (H05) and 39\% (D02) greater yield than the parents (Table 1); in comparison, in each of the IRR trials, the ten best genotypes yielded only $9 \%$ more than the parents (Table 1). When compared with the parents (Table 1), the ten best yielding genotypes across trials showed their highest yields under D02 and H05 (68\% and $30 \%$ more than the parental mean, respectively). The maximum range of anthesis recorded was 18 days in I06 (Table 1). Heritability across trials for yield, anthesis, and TGW is presented in Table 1, and show similar values for the three traits in all of the trials.

Associations between agronomic and physiological traits

The phenotypic correlations across years of HOT, DRT, and IRR yield were $0.68,0.66$, and 0.56 , respectively, while correlations for grain yield across environments varied from 0.48 to 0.74 (Fig. 1). Phenotypic and genotypic correlations between yield and the remaining traits were calculated, and the significant correlations are reported (Table 3). In terms of yield components, $\mathrm{GM}^{-2}$ showed relatively large and consistent correlations with yield in all environments, while KWI was weakly associated with yield (Table 3). There was a general trend for earliness to be associated with better performance in most environments, even within the narrow range observed here. Consistent negative correlations with yield were observed for CTv and CTg (high temperatures) in the stressed environments but not in IRR (Table 3). The spectral index (NDVIv) showed an association with yield in all environments being stronger under both stress environments. CHLg showed moderate to high association with yield and was strongly related under DRT. The association of WSC with yield was significant but showed some direction inconsistencies across environments.

For each trait, its heritability calculated across all environments $\left(h_{\mathrm{G} \text { ALL }}^{2}\right)$ or across stress environments $\left(h_{\mathrm{G}}\right.$ $\mathrm{DH}^{2}$ ) did not change substantially (Table 3 ). The most heritable traits were anthesis and maturity $(>0.9)$. Comparing only the agronomic traits, TGW had the highest heritability, grain number $\left(\mathrm{GM}^{-2}\right)$, and KWI reported heritabilities $>0.5$. From the physiological traits, WSC and 
Fig. 1 Trait association for yield across all six trials of the Seri/Babax population grown between 2002 and 2006. The diagonal contains the yield histogram for each trial, the lower diagonal a scatter plot and loess smoothing line between all trials, and the upper diagonal contains the phenotypic correlations

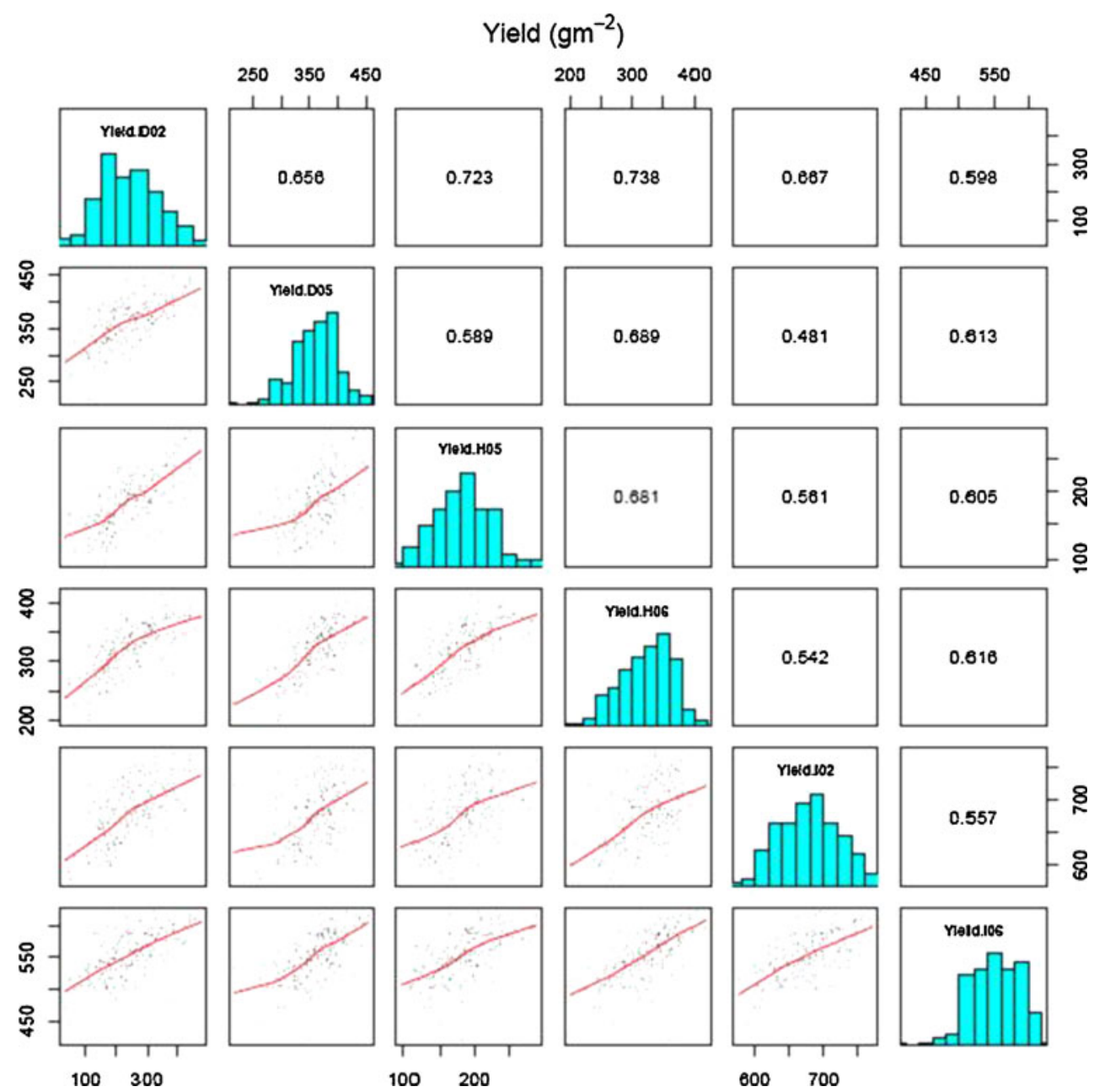

Table 3 Phenotypic (P) and genotypic (G) correlations of yield with agronomic, phenological, and physiological traits, and heritability across all environments $\left(h_{\mathrm{G} \mathrm{ALL}}^{2}\right)$ and across heat and drought environments $\left(h_{\mathrm{G} \mathrm{HD}}^{2}\right)$

\begin{tabular}{|c|c|c|c|c|c|c|c|c|c|c|c|c|c|c|}
\hline \multirow[t]{2}{*}{ Trait } & \multicolumn{2}{|l|}{ D02 } & \multicolumn{2}{|l|}{ D05 } & \multicolumn{2}{|l|}{ H05 } & \multicolumn{2}{|l|}{ H06 } & \multicolumn{2}{|l|}{ I02 } & \multicolumn{2}{|l|}{ I06 } & \multirow[t]{2}{*}{$h_{\mathrm{G} \mathrm{ALL}}^{2}{ }^{\mathrm{a}}$} & \multirow[t]{2}{*}{$h_{\mathrm{G} \mathrm{DH}}^{2}$} \\
\hline & $\mathrm{P}$ & $\mathrm{G}^{\mathrm{a}}$ & $\mathrm{P}$ & $\mathrm{G}^{\mathrm{a}}$ & $\mathrm{P}$ & $\mathrm{G}^{\mathrm{a}}$ & $\mathrm{P}$ & $\mathrm{G}^{\mathrm{a}}$ & $\mathrm{P}$ & $\mathrm{G}^{\mathrm{a}}$ & $\mathrm{P}$ & $\mathrm{G}^{\mathrm{a}}$ & & \\
\hline $\mathrm{GM}^{-2}$ & 0.977 & 0.998 & 0.729 & 0.604 & 0.949 & 0.962 & 0.801 & 0.792 & 0.637 & 0.589 & 0.465 & 0.655 & 0.544 & 0.605 \\
\hline TGW & 0.421 & 0.410 & 0.604 & 0.717 & NS & NS & NS & NS & NS & NS & 0.378 & 0.468 & 0.848 & 0.808 \\
\hline KWI & NR & NR & 0.333 & 0.400 & NS & 0.221 & NS & 0.238 & NR & NR & NS & -0.260 & 0.596 & 0.577 \\
\hline Anthesis & -0.677 & -0.783 & -0.266 & -0.268 & -0.512 & -0.570 & -0.331 & -0.340 & -0.436 & -0.542 & -0.473 & -0.621 & 0.937 & 0.918 \\
\hline Maturity & -0.339 & -0.453 & NS & NS & -0.377 & -0.406 & NS & NS & -0.370 & -0.434 & -0.374 & -0.510 & 0.933 & 0.921 \\
\hline Height & 0.767 & 0.825 & 0.20 & 0.229 & NS & NS & 0.368 & 0.431 & NS & NS & NS & -0.264 & 0.745 & 0.693 \\
\hline $\mathrm{CTv}$ & -0.589 & -0.924 & NR & NR & -0.676 & -0.597 & -0.829 & -0.873 & NR & NR & -0.397 & -0.385 & $\mathrm{NC}$ & $\mathrm{NC}$ \\
\hline $\mathrm{CTg}$ & -0.618 & -0.835 & -0.547 & -0.425 & NS & -0.312 & -0.393 & -0.231 & NS & 0.641 & NS & -0.317 & 0.494 & 0.472 \\
\hline NDVIv & 0.516 & 0.734 & NS & $\mathrm{NC}$ & 0.298 & 0.505 & 0.580 & 0.785 & NR & NR & NS & 0.352 & 0.294 & 0.331 \\
\hline NDVIg & -0.296 & -0.425 & NS & 0.352 & 0.331 & 0.469 & NS & 0.402 & NR & NR & NS & -0.462 & 0.712 & 0.688 \\
\hline CHLg & 0.249 & 0.900 & NS & NS & NS & NS & NS & NS & NS & NS & NS & 0.237 & 0.460 & 0.472 \\
\hline WSC & NR & NR & NS & 0.382 & 0.222 & 0.386 & NS & -0.389 & NR & NR & NS & -0.593 & 0.230 & 0.190 \\
\hline
\end{tabular}

$P$ phenotypic correlation with yield, $G$ genotypic correlation with yield, $h_{\mathrm{G} \text { ALL }}^{2}$ heritability calculated across all environments, $h_{\mathrm{G}}^{2}$ DH heritability calculated across heat and drought environments, $N R$ not recorded data, $N C$ not calculated, $N S$ not significant at $\alpha=0.05$

${ }^{\text {a }}$ Genotypic correlation and heritabilities were calculated only for $(\mathrm{Vg} / \mathrm{SE}$ of $\mathrm{Vg})>2$ 
NDVIv reported the lowest heritabilities (Table 3), and all the rest showed moderate to high values.

QTL mapping results for agronomic, phenological, and physiological traits

In total, 115 trait $\times$ environment $\times$ year combinations were analyzed for QTL. Of these, 109 combinations were associated with at least one significant QTL (see Supplementary Table 1 for the complete table of results). The QTL related to agronomic, phenological, and physiological traits averaged LOD scores of 2.92, 3.5, and 3.56, respectively. The average LOD for all significant QTL (LOD $>2$ ) was 3.6 with maximum of 15 (see Supplementary Fig. 2 for LOD score distribution). A summary of the results is presented as a matrix of linkage groups by traits in Table 4; shading indicates repeatable (across years), stress, and robust (across environments) QTL (different font formats differentiate between these three groups); unshaded cells indicate QTL that did not appear in both years of any single environment. Table 5 shows the markers (and flanking markers) related to the largest effects in each repeatable, robust or stress QTL, and also other traits with QTL at the same marker. Except for D02, the greatest phenotypic variances $\left(R^{2}\right)$ in all the environments $\times$ year combinations were associated with QTL of traits other than yield; maximum $\% R^{2}$ values explained by markers associated with repeatable, robust, and stress QTL are presented in Supplementary Table 2. Not all markers of each QTL are listed, the criteria being to include only consistent QTL with markers showing an $R^{2}>10 \%$ for at least one trait $\times$ environment $\times$ year combination.

The 109 combinations were related to 104 significant QTL (across the 28 linkage groups), of which 14, 16, and 10 QTL were associated exclusively with DRT, HOT, and IRR environments, respectively, and 94 were associated with stress although not necessarily exclusively (Table 4). From the 104 QTL detected, 7 were repeatable, 17 were stress QTL, and 14 robust QTL. In addition, 9 linkage groups appear to contain two QTL for the same trait (Table 4; Supplementary Fig. 1). Including suggestive QTL, 1B-a contained the most QTL (10) related to yield, $\mathrm{GM}^{-2}$, CT, NDVI, and CHLg. All traits were related to multiple genomic regions with six linkage groups $1 \mathrm{~B}-\mathrm{a}, 2 \mathrm{~B}-\mathrm{a}, 3 \mathrm{~B}-\mathrm{b}, 4 \mathrm{~A}-\mathrm{a}$, 4A-b, and 5A-a (Table 4; Supplementary Fig. 1) being identified as being most significant in controlling the traits studied based on the number of QTL signals detected. Grain yield was associated with QTL on eight different linkage groups; all of them were identified under DRT while 6 and 7 were detected under HOT and IRR environments, respectively (Supplementary Fig. 1). Six genomic regions were related mainly to yield, $\mathrm{CT}$, and $\mathrm{GM}^{-2}$ with positive contributions mainly from Babax alleles (linkage groups 1B-a, 3B-b, and 4A-a), but some effects also from Seri on linkage groups 2B-a and 6B-a (Fig. 2). All QTL are represented in Supplementary Fig. 1; however, Fig. 2 shows that yield, $\mathrm{GM}^{-2}$, and CT were associated with QTL on at least five of the same linkage groups: 1B-a, 2B-a, 3B-b, 4A-a, 4B-b, and 6B-a.

QTL related to agronomic traits

Of the eight QTL related to yield, four were robust (i.e. across stressed and irrigated environments) appearing in linkage groups 1B-a, 3B-b, 4A-a, and 4A-b (Tables 4, 5; Supplementary Table 1). However, considering that distances greater than $30 \mathrm{cM}$ between markers with LOD $>2$ may indicate different QTL it is possible that linkage groups 3B-b and 4A-b contained more than one QTL for yield (Table 4; Supplementary Table 1). No repeatable yield QTL were detected as unique for any given environment. The QTL for yield in 1B-a appeared in all environments and were associated with markers mainly located in the region of the rye translocation (see below). The additive effects of all significant QTL expressed under DRT explained the largest proportion of variation in yield when compared with the other environments (Fig. 3). The strongest effect for yield $\left(47 \mathrm{~g} \mathrm{~m}^{-2}\right)$ of any QTL was found in linkage group 4A-a under DRT, and the largest favorable effects on yield were contributed by the Babax allele.

On linkage group 1B-a, there was co-location of yield QTL with QTL for $\mathrm{GM}^{-2}$, NDVIv, CTv, CTg, and WSC (Table 4). Except for WSC, all these traits were found to be significantly correlated with yield (Table 3 ). In the 1B-a region, yield increases as well as the increases in $\mathrm{GM}^{-2}$ and NDVIv were usually controlled by the Babax allele (Figs. 3, 5), but warmer (unfavorable) canopy temperatures were generally dominated by the Seri allele while higher WSC contents were associated with both parental alleles (Fig. 5). Repeatable, stress, and robust QTL for $\mathrm{GM}^{-2}$ that coincided with those for yield were found on 1B-a, 3B-b, and 4A-a (Table 4). The strongest effect for $\mathrm{GM}^{-2}\left(654\right.$ grains $\left./ \mathrm{m}^{2}\right)$ was located on $1 \mathrm{~B}-\mathrm{a}$, with a $\% R^{2}$ of $11.8 \%$; other traits associated with this marker were yield, height, CTv, CTg, NDVIv, CHLg, and WSC (Table 5). This QTL was robust and associated with the presence of the Babax (non-rye) allele, being detected under DRT, IRR and both years of HOT (Supplementary Table 1). It was also associated with the location of the third largest QTL effect for yield. On the $5 \mathrm{~B}-\mathrm{a}$ linkage group, the $\mathrm{GM}^{-2} \mathrm{QTL}$ detected was repeatable for both years of the HOT treatment. Favorable effects from Seri and from Babax alleles (Fig. 3) were found for $\mathrm{GM}^{-2}$, but the expression of QTL showed the strongest additive effects were dominated by the Babax allele under the HOT environments. The strongest QTL effects for TGW were found on linkage groups 3B-a, 4A-b, and 4B-b (Table 4; Supplementary Table 1); the greatest repeatable effects for TGW were found in IRR environment (Fig. 3) mainly 
Table 4 Summary of significant QTL found for all traits across environments showing the marker related to the maximum phenotypic variance $\left(\% R^{2}\right)$ for each trait and its corresponding linkage group and position

\begin{tabular}{|c|c|c|c|c|c|c|c|c|c|c|c|c|c|}
\hline Linkage group & Yield & $\mathrm{GM}^{-2}$ & TGW & KWI & ANTH & MAT & Height & CTV & $\mathrm{CTg}$ & NDVIV & NDVIg & CHLg & WSC \\
\hline $1 \mathrm{~A}-\mathbf{a}$ & & & $1 / 6$ & $2 / 4$ & & & & & $2 / 6$ & & & $1 / 6$ & \\
\hline 1A-b & & & & & & $2 / 6$ & & $1 / 4$ & $1 / 6$ & & & & $2 / 4$ \\
\hline $1 \mathrm{~B}-\mathrm{a}$ & $6 / 6$ & $4 / 6$ & & & $1 / 6$ & & $1 / 6$ & $3 / 4$ & $3 / 6$ & $3 / 5$ & $2 / 5$ & $3 / 6$ & $2 / 4$ \\
\hline 1D-a & & & & & & & & & $1 / 6$ & & & $2 / 6$ & \\
\hline 1D-b & $2 / 6$ & & & & $4 / 6$ & $4 / 6$ & & & & $1 / 5$ & $1 / 5$ & $2 / 6$ & \\
\hline $2 A-c$ & & & & & & & & & & & & & \\
\hline 2B-a & & & $2 / 6$ & $3 / 4$ & & $2 / 6$ & $2 / 6$ & $3 / 4$ & $3 / 6$ & & $2 / 5$ & & \\
\hline 2B-b & & & & & & & & & & & & & \\
\hline 2D-a & & & & & & & & & & & & & \\
\hline 3A-a & & & & & & & & & & & & $1 / 6$ & \\
\hline 3A-b & $3 / 6$ & & & & & & & & & & & & $1 / 4$ \\
\hline 3B-a & & $2 / 6$ & $2 / 6$ & $1 / 4$ & & & & & $1 / 6$ & & & & \\
\hline 3B-b & $4 / 6^{c}$ & $3 / 6$ & $1 / 6$ & & & & $2 / 6^{\mathrm{c}}$ & $3 / 4$ & $5 / 6$ & $2 / 5$ & & $2 / 6$ & $1 / 4^{\mathrm{c}}$ \\
\hline $4 \mathrm{~A}-\mathrm{a}$ & $5 / 6$ & $4 / 6$ & & & & & $2 / 6^{\mathrm{d}}$ & $4 / 4$ & $2 / 6$ & $3 / 5$ & $3 / 5$ & & $1 / 4$ \\
\hline 4A-b & $3 / 6^{\mathrm{c}}$ & $1 / 6$ & $3 / 6^{\mathrm{c}}$ & & & & $2 / 6$ & $1 / 4$ & & $2 / 5^{\mathrm{c}}$ & & & $1 / 4$ \\
\hline 4B-b & $2 / 6$ & $1 / 6$ & $3 / 6$ & & & & $3 / 6$ & $3 / 4$ & & & $2 / 5$ & & \\
\hline 4D-a & & $1 / 6$ & & & $5 / 6$ & $2 / 6$ & & & & & & & \\
\hline $5 \mathrm{~A}-\mathrm{a}$ & & & & & $3 / 6$ & $3 / 6$ & & & $4 / 6^{\mathrm{c}}$ & $2 / 5$ & $2 / 5$ & $1 / 6$ & $1 / 4$ \\
\hline $5 \mathrm{~B}-\mathrm{a}$ & & $2 / 6$ & $2 / 6$ & $1 / 4$ & & & $1 / 6$ & $1 / 4$ & $1 / 6$ & & & & \\
\hline $6 \mathrm{~A}-\mathrm{a}$ & & & $2 / 6$ & $2 / 4$ & & & & & & $2 / 5$ & $2 / 5$ & & \\
\hline $6 A-b$ & & & & & & & & & & & & & \\
\hline $6 \mathrm{~B}-\mathrm{a}$ & $3 / 6^{\mathrm{c}}$ & $3 / 6$ & & $1 / 4$ & & $1 / 6$ & & $1 / 4$ & & & $1 / 5$ & & \\
\hline 6D-a & & & & & & & & & & & & & \\
\hline 6D-b & & $1 / 6$ & & & & & & & & & & & \\
\hline $7 \mathrm{~A}-\mathrm{a}$ & & & & & & & & $3 / 4$ & $3 / 6^{\mathrm{c}}$ & $2 / 5^{\mathrm{d}}$ & & & \\
\hline $7 \mathrm{~B}-\mathrm{a}$ & & & & & $1 / 6$ & $3 / 6$ & & & & & $3 / 5$ & & \\
\hline UA- $\mathrm{a}^{\mathrm{b}}$ & & & & & & & & & & & & & \\
\hline $\mathbf{U A - b ^ { b }}$ & & & & & & & & & $2 / 6$ & & & & \\
\hline${ }^{\mathrm{a}} \operatorname{Max} \% \mathbf{R}^{2}$ & 27.4 & 16.9 & 13.0 & 14.5 & 11.5 & 11.2 & 12.1 & 27.6 & 11.2 & 24.2 & 13.2 & 14.0 & 33.5 \\
\hline Marker & aac/letg-3 & aac/lg-3 & gwm518b & acalcta-2 & gwm301d & gwm301d & $\mathrm{aag} / \mathrm{ctc}-1$ & aac/tg-3 & act/cag-2 & agg/cat-4 & $\mathrm{agg} / \mathrm{cta}-12$ & aac/ac-5 & aac/teg-3 \\
\hline Linkage group & 4A-a & $4 \mathrm{~A}-\mathrm{a}$ & $6 \mathrm{~A}-\mathrm{a}$ & $1 \mathrm{~A}-\mathrm{a}$ & 1D-b & 1D-b & 3B-b & $4 \mathrm{~A}-\mathrm{a}$ & UA-b & 1B-a & $4 \mathrm{~A}-\mathrm{a}$ & 3B-b & $4 \mathrm{~A}-\mathrm{a}$ \\
\hline Position (cM) & 22.8 & 22.8 & 72.7 & 33.2 & 0.0 & 0.0 & 60.4 & 14.8 & 8.0 & 61.0 & 14.2 & 33.1 & 18.8 \\
\hline
\end{tabular}

The number of trials where a QTL was found to be significant in each trait and linkage group is shown relative to the total number of trials in which the trait was measured

Shaded cells: main effects QTL present in at least both years of one environment, classified as repeatable (2 years of an environment-normal font), stress ( 2 years of one stress environment and at least 1 year of the other stress-bold font), robust ( 2 years of a stress environment and at least 1 year of irrigated, or vice versa-italic font)

Unshaded cells: suggestive QTL effects that did not appear in 2 years of any environment

a Maximum variance explained by a QTL associated with the trait across trials

b Unassigned linkage group

${ }^{c}$ Linkage groups that may contain two QTL related to a single trait

${ }^{\mathrm{d}}$ In this linkage group, the makers are slightly further than $30 \mathrm{cM}$ apart

associated with the Seri allele in the 4B-b region (Table 5). The largest effects for KWI were found in the HOT environment, and the trait was increased by Seri alleles on $2 \mathrm{~B}-\mathrm{a}$ and by Babax alleles on 1A-a, 3B-a, and 6B-a (Fig. 3).

QTL related to phenological traits and height

Diverse genomic regions were found to contain QTL related to the phenological traits, and some of them were common between anthesis and maturity, which is consistent with the high genetic correlation between these traits averaged across experiments (data not shown, $R^{2}=0.79$ ). Three main regions affected anthesis date: 1D-b, 4D-a, and
5A-a (Table 4). The QTL located in the first two regions were classified as robust, while the QTL on $5 \mathrm{~A}$-a was found to be specific for stress. Linkage group 1D-b showed the strongest additive effects under DRT and IRR (0.51.3 days) contributed by the Babax allele (Fig. 4); conversely, a similar size QTL effect on $4 \mathrm{D}$-a was contributed by a Seri allele in HOT environments (Table 5). The greatest QTL effects (ca. 1 day) were found in the IRR environment (Fig. 4). QTL for maturity were co-located with those for anthesis on 1A-b, 1D-b, 4D-a, 5A-a, and 7B-a (Table 4). The QTL at 1A-b and 4D-a were detected as repeatable under DRT and HOT, respectively; the QTL on $1 \mathrm{D}-\mathrm{b}$ was robust, and the QTL at $5 \mathrm{~A}-\mathrm{a}$ and $7 \mathrm{~B}-\mathrm{a}$ were 
Table 5 Markers (and flanking markers) associated with the highest additive effect across all trials where a consistent QTL was detected for each trait

\begin{tabular}{|c|c|c|c|c|c|c|}
\hline $\begin{array}{l}\text { Linkage } \\
\text { group }\end{array}$ & $\begin{array}{l}\text { Marker of }{ }^{a} \\
\text { max effect }\end{array}$ & $\operatorname{Max}^{\mathrm{b}}$ effect & $R^{2}(\%)$ & \multicolumn{2}{|c|}{ Flanking markers ${ }^{\mathrm{a}}$ of the QTL } & Other traits with QTL at this marker \\
\hline \multicolumn{7}{|c|}{ Yield $\left(\mathrm{g} \mathrm{m}^{-2}\right)$} \\
\hline $1 \mathrm{~B}-\mathrm{a}$ & wPt-2052 (90.16) & 35.5B-D02 & 10.5 & wPt-5281 (32.81) & agg/ctg-3 (130.33) & $\mathrm{GM}^{-2}$, NDVIv \\
\hline $3 \mathrm{~B}-\mathrm{b}$ & wPt-1804 (120.09) & 38.2B-D02 & 15.1 & aag/ctc-1 (62.35) & acc/ctc-8 (137.4) & CTv.CTg \\
\hline $4 \mathrm{~A}-\mathrm{a}$ & act/cag-5 (11.63) & 47.0B-D02 & 23.9 & gwm397 (6.01) & aac/ctg-3 (24.77) & $\mathrm{GM}^{-2}, \mathrm{CTV}$ \\
\hline $4 \mathrm{~A}-\mathrm{b}$ & wPt-7821 (48.85) & 16.9S-D02 & 3.1 & aca/cta-8 (0.01) & wPt-7821 (48.85) & Height \\
\hline \multicolumn{7}{|l|}{$\mathrm{GM}^{-2}$} \\
\hline $1 \mathrm{~B}-\mathrm{a}$ & $\operatorname{barc065}(64.39)$ & 654B-H06 & 11.8 & wPt-5281 (34.81) & aca/cag-5 (96.15) & $\begin{array}{l}\text { YIELD, Height, CTv, CTg, NDVIv, } \\
\text { CHLg, WSC }\end{array}$ \\
\hline $3 B-b$ & wPt-0021 (129.23) & 344B-H06 & 4.4 & wPt-0021 (129.23) & acc/ctc-8 (147.4) & YIELD, TGW, CTv, CTg, NDVIv, WSC \\
\hline $4 \mathrm{~A}-\mathrm{a}$ & act/cag-5 (11.63) & 574B-H06 & 12.5 & act/cag-5(9.63) & aac/ctg-3 (26.77) & YIELD, Height, CTv, CTg, NDVIg, WSC \\
\hline $5 \mathrm{~B}-\mathrm{a}$ & wPt-9814 (6.29) & 338S-H05 & 5.7 & wPt-9814 (6.29) & wPt-6726 (29.8) & KWI, CTv, CTg \\
\hline $6 \mathrm{~B}-\mathrm{a}$ & wPt-2786 (57.93) & 403S-H06 & 5.9 & wPt-2786 (57.93) & agg/ctg-8 (112.78) & \\
\hline \multicolumn{7}{|l|}{ TGW (g) } \\
\hline $3 \mathrm{~B}-\mathrm{a}$ & agg/cat-3 (17.3) & 0.746B-H05 & 9.8 & gwm389 (6.69) & agg/cat-3 (17.3) & KWI, CTg \\
\hline $4 \mathrm{~A}-\mathrm{b}$ & act/cag-4 (21.24) & $0.714 \mathrm{~S}-\mathrm{D} 05$ & 5.4 & act/cag-4 (21.24) & agg/cat-9 (111.51) & \\
\hline $4 \mathrm{~B}-\mathrm{b}$ & aag/cta-5 (38.22) & $1.41 \mathrm{~S}-\mathrm{I} 06$ & 6.5 & aag/cta-5 (38.22) & wPt-1708 (44.44) & YIELD, Height, CTv \\
\hline \multicolumn{7}{|c|}{ ANTH (days) } \\
\hline $1 \mathrm{D}-\mathrm{b}$ & gwm301d (0.01) & 1.3184B-I06 & 10.8 & gwm301d (0.01) & aag/ctg-2 (8.05) & MAT, CHLg \\
\hline $4 \mathrm{D}-\mathrm{a}$ & $\operatorname{cfd023~(4.06)~}$ & $1.2554 \mathrm{~S}-\mathrm{H} 06$ & 11.4 & $\operatorname{cfd} 023(4.06)$ & $\operatorname{cfd} 023(6.06)$ & $\mathrm{GM}^{-2}$, MAT \\
\hline $5 \mathrm{~A}-\mathrm{a}$ & aac/ctc-12 (66.36) & 0.851B-H05 & 7.7 & aag/ctg-10 (25.54) & aac/ctc-12 (66.36) & \\
\hline \multicolumn{7}{|c|}{ MAT (days) } \\
\hline $1 \mathrm{~A}-\mathrm{b}$ & wPt-0432 (0.01) & $0.5732 \mathrm{~S}-\mathrm{D} 05$ & 4.9 & wPt-0432 (0.01) & wPt-8644 (15.92) & $\mathrm{CTg}$ \\
\hline $1 \mathrm{D}-\mathrm{b}$ & gwm301d (0.01) & 0.834B-I06 & 11.2 & gwm301d (0.01) & act/ctc-4 (3.65) & ANTH, CHLg \\
\hline $4 \mathrm{D}-\mathrm{a}$ & $\operatorname{cfd} 023(6.06)$ & $1.0236 \mathrm{~S}-\mathrm{H} 05$ & 7.6 & $\operatorname{cfd} 023$ & $\operatorname{cfd} 023(6.06)$ & $\mathrm{GM}^{-2}, \mathrm{ANTH}$ \\
\hline $5 \mathrm{~A}-\mathrm{a}$ & acc/ctg-7 (46.55) & 0.7101B-D05 & 7.8 & aag/ctg-10 (25.54) & gwm304 (62.02) & NDVIg, CHLg \\
\hline $7 \mathrm{~B}-\mathrm{a}$ & acc/ctc-7 (9.28) & 0.916S-H05 & 7.4 & $\operatorname{gdm} 086(0.01)$ & acc/ctc-7 (9.28) & ANTH, NDVIg \\
\hline \multicolumn{7}{|c|}{ Height (cm) } \\
\hline $4 \mathrm{~B}-\mathrm{b}$ & gwm006a (26.44) & 1.6329S-D05 & 10.55 & wPt-0391 (12.57) & wPt-1708 (50.44) & YIELD, $\mathrm{GM}^{-2} \mathrm{ICTV}$ \\
\hline \multicolumn{7}{|c|}{$\mathrm{CTV}\left({ }^{\circ} \mathrm{C}\right)$} \\
\hline $1 \mathrm{~B}-\mathrm{a}$ & wPt-3465 (70.62) & 0.3889B-H06 & 3.3 & aca/cac-5 (53.8) & aca/cag-5 (96.15) & YIELD, GM $^{-2}$, Height, NDVIv, WSC \\
\hline $2 \mathrm{~B}-\mathrm{a}$ & acc/ctg-4 (26.94) & $0.2264 \mathrm{~B}-\mathrm{H} 06$ & 11.9 & aac/cta-1 (7.52) & agg/cta-3 (75.84) & MAT, CTg \\
\hline $3 \mathrm{~B}-\mathrm{b}$ & acc/ctc-8 (135.4) & $0.2372 \mathrm{~S}-\mathrm{H} 06$ & 11.3 & wPt-1804 (120.09) & acc/ctc-8 (141.4) & $\begin{array}{l}\text { YIELD, GM }{ }^{-2}, \text { TGW, Height, CTg, } \\
\text { NDVIv, WS C }\end{array}$ \\
\hline $4 \mathrm{~A}-\mathrm{a}$ & agg/cta-12 (14.23) & $0.4598 \mathrm{~S}-\mathrm{H} 06$ & 26.3 & gwm397 (4.01) & aac/ctg-3 (24.77) & $\mathrm{GM}^{-2}$, Height, CTg, NDVIv, NDVIg \\
\hline $7 \mathrm{~A}-\mathrm{a}$ & aag/cta-7 (247.87) & 0.1999S-H06 & 7.6 & wPt-2260 (216.48) & aag/cta-7 (247.87) & $\mathrm{CTg}$ \\
\hline \multicolumn{7}{|c|}{$\mathrm{CTg}\left({ }^{\circ} \mathrm{C}\right)$} \\
\hline $1 \mathrm{~B}-\mathrm{a}$ & agc/cta-9 (80.66) & $0.211 \mathrm{~S}-\mathrm{D} 02$ & 6.9 & wPt-5281 (34.81) & aca/caa-3 (101.24) & YIELD, NDVIv, WSC \\
\hline $2 \mathrm{~B}-\mathrm{a}$ & gwm388 (45.59) & 1.2366B-D05 & 5.9 & wPt-9668 (0.01) & gwm388 (45.59) & CTv, NDVIg \\
\hline $3 B-b$ & wPt-1804 (116.09) & 0.2109S-H05 & 7.1 & wPt-1804 (112.09) & acc/ctc-8 (161.4) & YIELD, CTv, NDVIv \\
\hline $5 \mathrm{~A}-\mathrm{a}$ & barc186 (55.32) & $0.1508 S-D 05$ & 6.4 & wPt-1165 (2.01) & barc100 (85.66) & ANTH \\
\hline $7 \mathrm{~A}-\mathrm{a}$ & aag/cta-7 (247.87) & $0.1082 S-D 05$ & 6.3 & agc/cag-6 (37.5) & aag/cta-7 (247.87) & $\mathrm{CTv}$ \\
\hline UA-b & aag/ctg-17 (17.6) & 0.8839B-D05 & 8.6 & act/cag-2 (8.01) & aag/ctg-17 (17.6) & \\
\hline \multicolumn{7}{|l|}{ NDVIv } \\
\hline $1 \mathrm{~B}-\mathrm{a}$ & agg/cat-4 (60.98) & 0.0269B-H05 & 24.2 & wPt-0170 (58.11) & aca/caa-3 (101.24) & YIELD, ANTH, CTv, CTg, NDVIg \\
\hline $4 \mathrm{~A}-\mathrm{b}$ & wPt-2345 (75.12) & $0.0082 \mathrm{~B}-\mathrm{H} 05$ & 7.9 & wPt-2345 (75.12) & aac/ctg-5 (108) & \\
\hline
\end{tabular}


Table 5 continued

\begin{tabular}{|c|c|c|c|c|c|c|}
\hline $\begin{array}{l}\text { Linkage } \\
\text { group }\end{array}$ & $\begin{array}{l}\text { Marker of }{ }^{\mathrm{a}} \\
\text { max effect }\end{array}$ & $\operatorname{Max}^{\mathrm{b}}$ effect & $R^{2}(\%)$ & \multicolumn{2}{|c|}{ Flanking markers ${ }^{\mathrm{a}}$ of the QTL } & Other traits with QTL at this marker \\
\hline \multicolumn{7}{|l|}{ NDVIg } \\
\hline $2 \mathrm{~B}-\mathrm{a}$ & agg/cac-5 (42.25) & 0.0206S-D02 & 8.1 & acc/ctc-2 (24.72) & aag/ctg-12 (53.1) & TGW, KWI, MAT, Height, CTv, CTg \\
\hline $4 \mathrm{~A}-\mathrm{a}$ & agg/cta-12 (14.23) & 0.0155-H06 & 13.2 & act/cag-5 (9.63) & agg/cta-12 (14.23) & $\mathrm{GM}^{-2}$, Height, CTv, CTg, NDVIv \\
\hline $7 \mathrm{~B}-\mathrm{a}$ & acc/ctc-7 (9.28) & $0.0172 \mathrm{~S}-\mathrm{D} 02$ & 5.6 & $\mathrm{aca} / \mathrm{cac}-7(5.63)$ & acc/ctc-7 (9.28) & ANTH, MAT \\
\hline \multicolumn{7}{|c|}{ CHLg (spad) } \\
\hline $1 \mathrm{~B}-\mathrm{a}$ & aac/ctg-4 (59.24) & $0.6324 \mathrm{~S}-\mathrm{H} 05$ & 10.1 & aac/ctg-4 (59.24) & wPt-8616 (96.1) & YIELD, $\mathrm{GM}^{-2}$, Height, CTv, CTg \\
\hline
\end{tabular}

The parent allele and trial are indicated

a In brackets the position of the marker

b Maximum effect found in each linkage group followed by the allele of the domain: $S$ allele of Seri, $B$ allele of Babax. At the end of the trial $\times$ year is indicated: $D$ drought, $H$ heat, $I$ irrigated

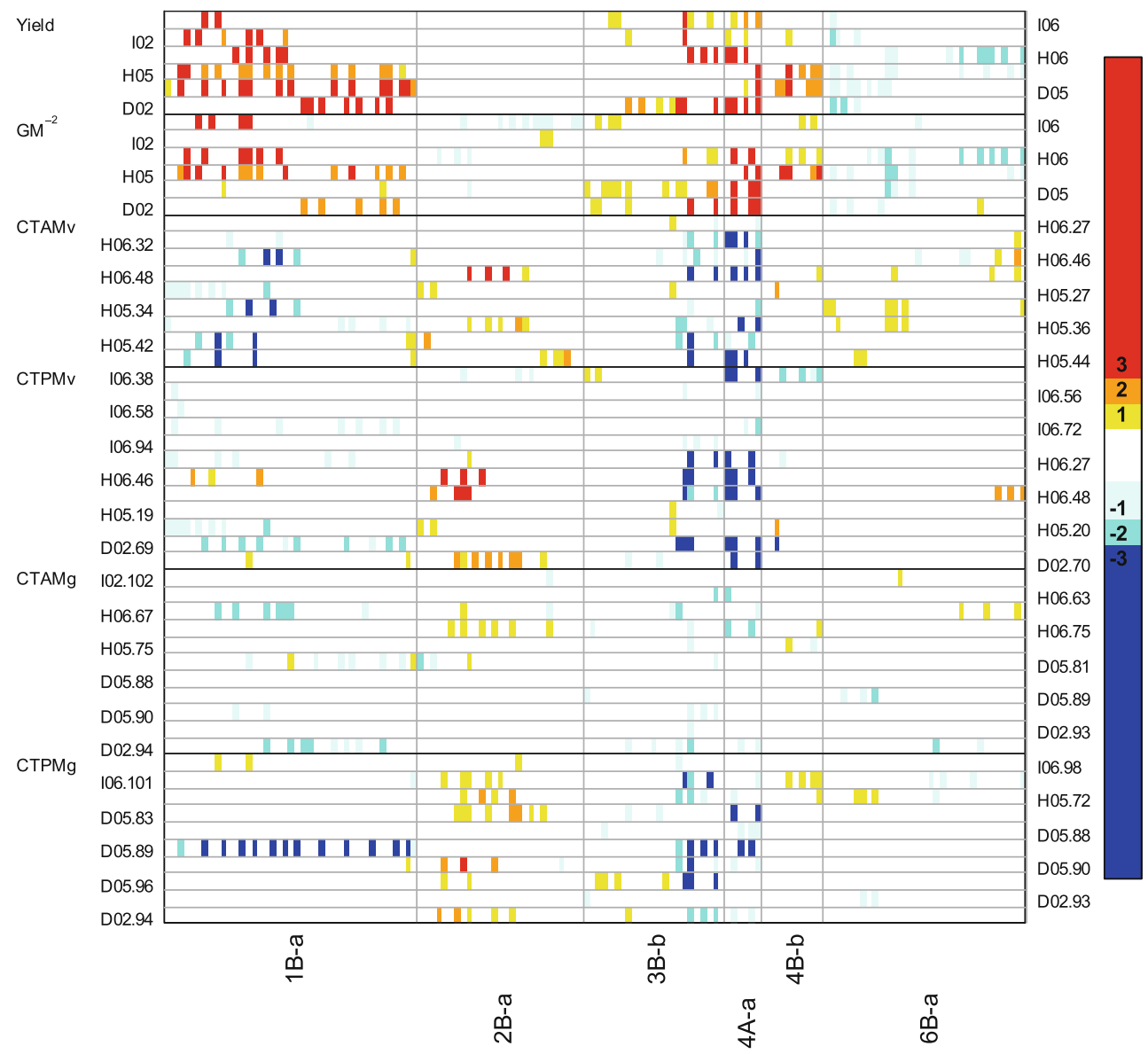

Linkage group (red = high value favoured by Babax allele)

Fig. 2 Main genomic regions associated with yield, grain number $\left(\mathrm{GM}^{-2}\right)$, and canopy temperature (CT) under drought $(\mathrm{D})$, heat $(\mathrm{H})$, and irrigated (I) environments. Blue and red colors are used to distinguish between Babax (red) and Seri (blue) LOD scores. On both

specifically associated with stress environments. The greatest effects for maturity (1 day) were found on 4D-a and were contributed by the Seri allele (Table 5; Supplementary Table 1) and in the HOT environments (Fig. 4; Supplementary Table 1). sides of the figure is indicated the corresponding trial $\times$ year, canopy temperature (CT) is additionally labeled with the date of measurement given in number of days after emergence

Most of the repeatable, robust, and stress QTL related to other traits were found in locations independent of the main regions controlling phenology. The exceptions were two: a robust QTL for CTg on 5A-a linkage group and one stress QTL for NDVIV 
Fig. 3 QTL effects for agronomic traits in the six trials. Positive (+) and negative (-) values are used to distinguish between additive effects of Babax and Seri alleles in each linkage group. Only effects where LOD $>2$ are shown
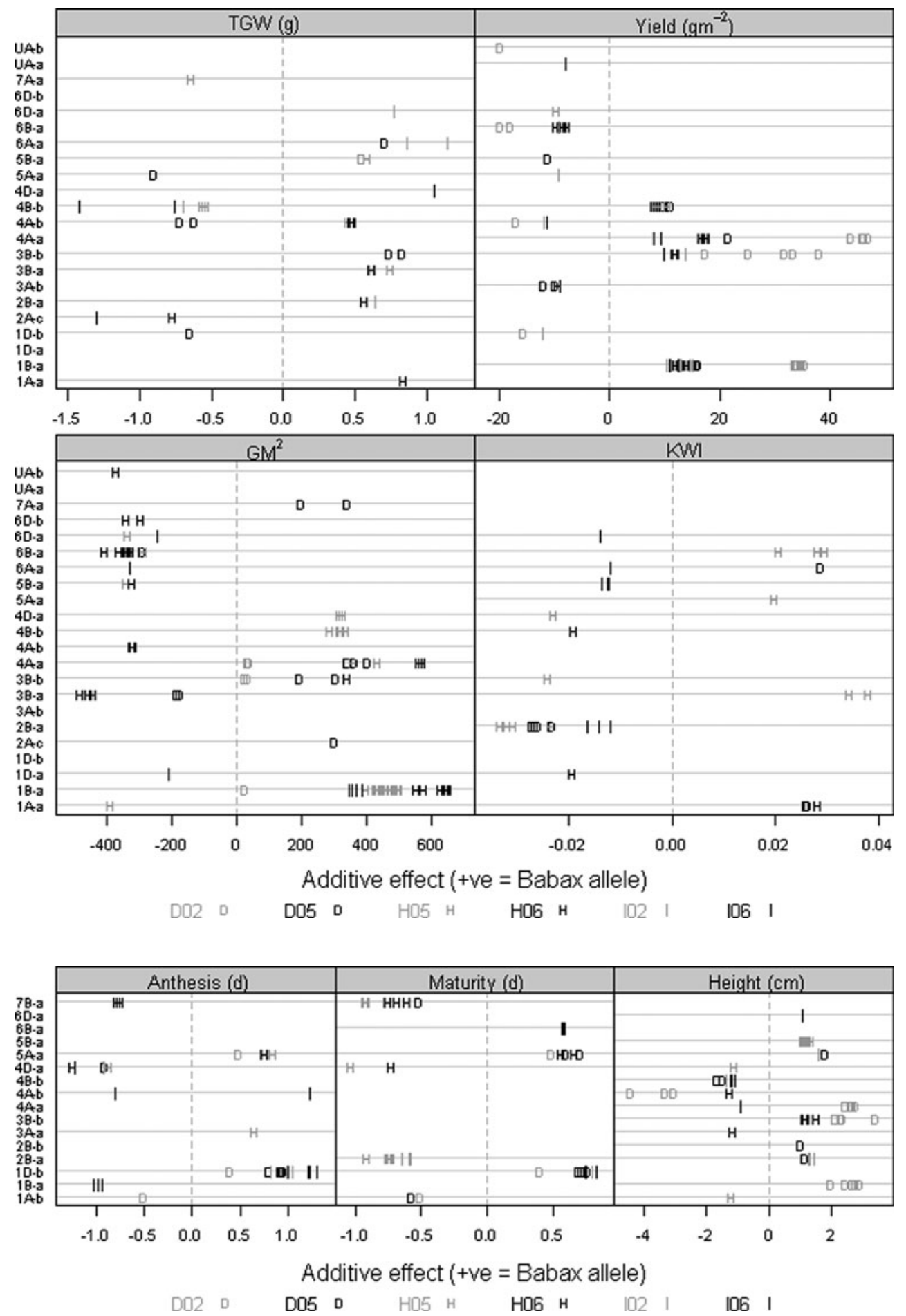

Fig. 4 QTL effects for the phenological traits. Positive $(+)$ and negative $(-)$ values are used to distinguish between additive effects of Babax and Seri alleles in each linkage group. Only effects where LOD $>2$ are shown linkage group 4A-b with the increased height alleles again from Seri (Fig. 4).

QTL related to physiological traits

The QTL for CTv were identified on linkage groups 1B-a, 2B-a, 3B-b, and 7A-a as exclusively related to stress environments (Table 4) and on 4A-a as robust across 
environments. Irrespective of the time of the measurement $(\mathrm{am} / \mathrm{pm})$, the greatest effects for $\mathrm{CTV}$ were found in the HOT environment (Fig. 5). Unfavorable effects (high CT) were dominated by the Seri allele, and the largest increases in CT $\left(0.46^{\circ} \mathrm{C}\right)$ were associated with the QTL on $4 \mathrm{~A}-\mathrm{a}$; other negative effects of Seri existed on 3B-b and 7A-a. Unfavorable effects from the Babax allele of similar magnitude were also detected, i.e. at $1 \mathrm{~B}-\mathrm{a}\left(0.39^{\circ} \mathrm{C}\right)$ and 2B-b, but they were less frequent than the Seri effects. Four QTL for CTg (three stress and one robust) were co-located with four stress QTL for CTv (Table 4). The QTL identified at 3B-b and 5A-a were robust, while at $1 \mathrm{~B}-\mathrm{a}, 2 \mathrm{~B}-\mathrm{a}$, and $7 \mathrm{~A}-\mathrm{a}$, the QTL were specific to stress environments
(Table 4). Two additional QTL were detected on 5A-a (robust) and UA-b (repeatable under DRT). Effects from alleles of both parents were found to be associated with CTg in both the morning and afternoon (Fig. 5), but the Seri allele was typically associated with the unfavorable increasing effect; the highest effects were detected in the DRT environment across diverse linkage group, i.e. increases of $1.5^{\circ} \mathrm{C}$ by a QTL on 4A-a (Fig. 5). NDVIvrelated QTL showed the most favorable increasing effects (0.027) in the 1B-a region, controlled by the Babax alleles (Fig. 5; Table 5). This trait showed one robust QTL in 1B-a and one repeatable QTL under HOT on 4A-b (Table 4); the HOT environment showed the strongest and

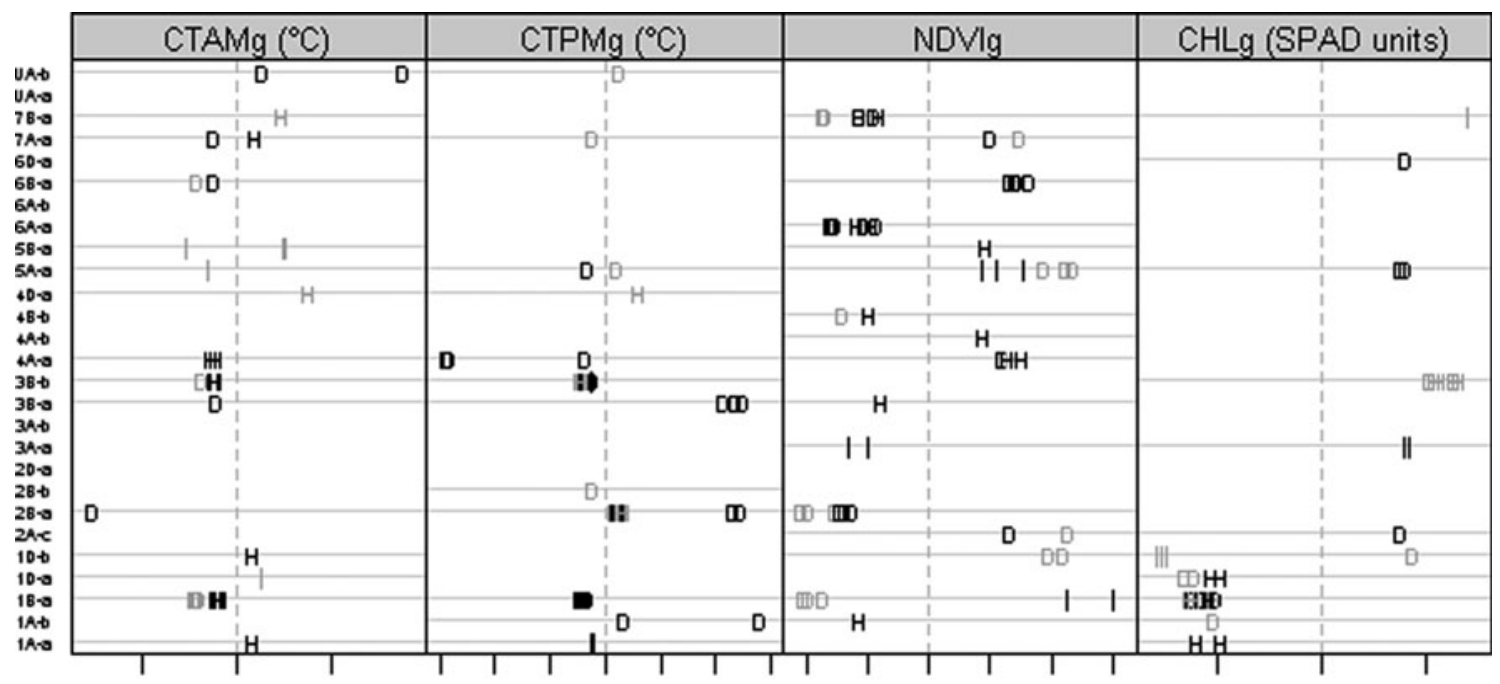

$\begin{array}{lllllllllllllllllllll}-0.5 & 0.0 & 0.5 & -1.5 & -1.0 & -0.5 & 0.0 & 0.5 & 1.0 & 1.50 .02 & -0.01 & 0.00 & 0.01 & 0.02 & 0.03 & & -0.5 & 0.0 & 0.5\end{array}$

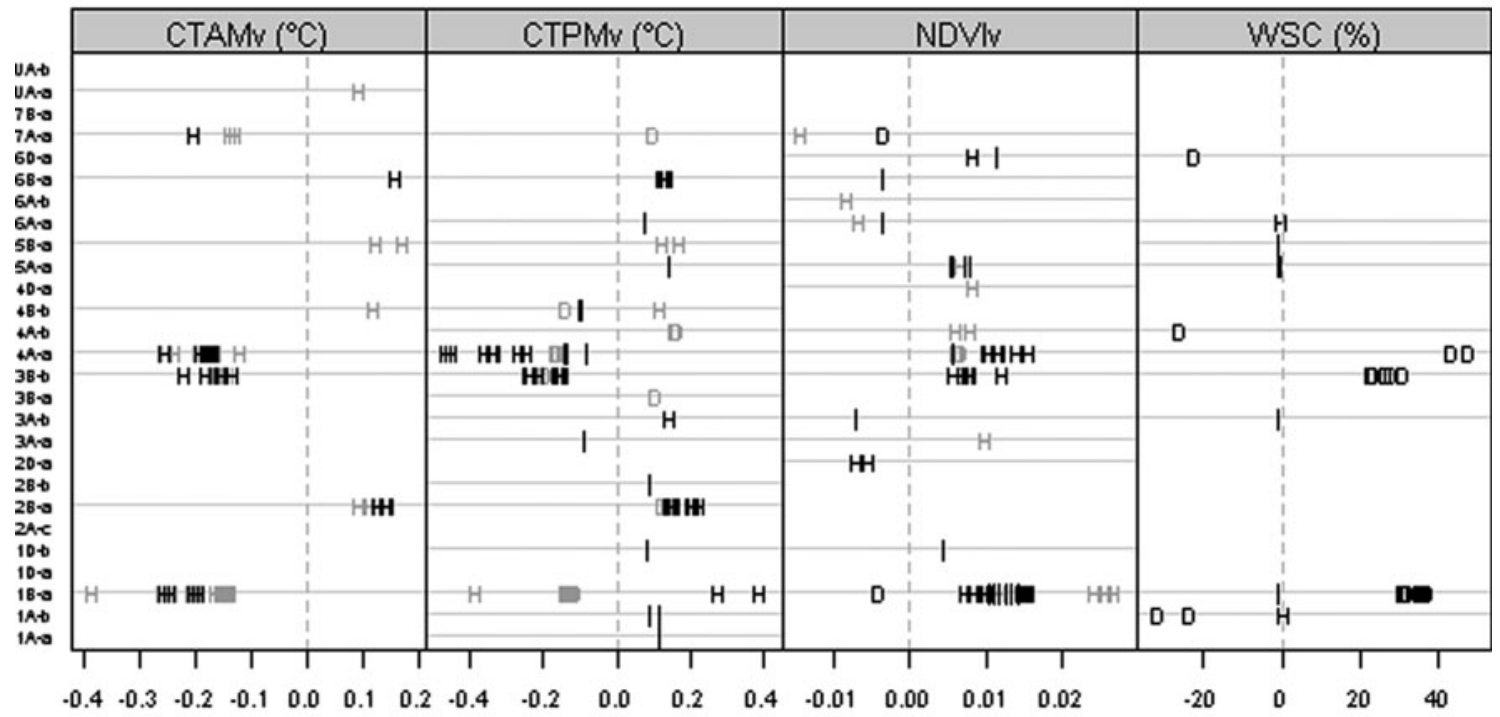

Additive effect (+ve = Babax allele)

D02 D D05 D H05 H H06 H 102 I 106 I

Fig. 5 QTL effects for the physiological traits. Positive (+) and negative (-) values are used to distinguish between additive effects of Babax and Seri alleles in each linkage group. Only effects where LOD $>2$ are shown 
most frequent significant effects for the NDVIv (Fig. 5). During grainfilling, NDVIg was associated with specific environments, and the QTL effects varied according to the environment and linkage groups. One repeatable QTL under DRT was detected at 2B-a and two stress QTL on 4A-a and 7B-a (Table 4). The highest effects were found in the IRR environment (Fig. 5) contributed by alleles of both parents. One stress QTL for CHLg was detected on 1B-a, with positive effects associated with the Seri allele (Table 4; Fig. 5); this QTL at 1B-a was co-located with a suggestive QTL associated with NDVIg; other coincident QTL were found on linkage groups 1D-b and 5A-a. The suggestive QTL found on 1D-b under DRT and IRR showed the highest effect (0.78) for the CHLg (Supplementary Table 1). Only suggestive QTL related to WSC were detected (Table 4); the most and the largest WSC QTL were identified under the DRT environment and were mainly contributed by the Babax allele (Fig. 5).

Common QTL associated with drought and heat adaptive traits

Co-locations of DRT and HOT QTL were frequently detected in this study, pointing to the potential existence of common adaptation mechanisms useful under both stress conditions. Common QTL were found for all traits in these two stress environments (17 stress QTL), with eight QTL co-located with QTL in IRR environments. The QTL exclusively related to both DRT and HOT environments (Table 4) were specific by trait and classified as stress QTL, as previously indicated. These stress QTL were found on linkage groups 3B-b, 4A-a, and 6B-a for $\mathrm{GM}^{-2}$; on $4 \mathrm{~A}-\mathrm{b}$ for TGW; on $5 \mathrm{~A}-\mathrm{a}$ for anthesis; on $5 \mathrm{~A}-\mathrm{a}$ and $7 \mathrm{~B}-\mathrm{a}$ for maturity; on 1B-a, 2B-a, 3B-b, and 7A-a for CT; on 4A$\mathrm{a}$ and 7B-a for NDVIg; and on 1B-a for CHLg (Table 4; Supplementary Table 1). A number of regions contained QTL in at least 1 year of both DRT and HOT environments, namely linkage groups 4B-b for yield; $3 \mathrm{~B}-\mathrm{a} \mathrm{GM}^{-2}$; 1A-a for KWI; 3B-b and 4A-b for height; 4A-a for CTg; 3B-b NDVIv; 4B-b, 6A-a for NDVIg; 1D-a, 3B-b for CHLg and 1A-b for WSC. An exploratory analysis for stress indexes (calculated as IRR-Stress/IRR) was conducted in order to detect QTL directly related to stress performance traits. The regions associated with the stress indexes confirmed the previously identified QTL (data no shown), but no novel locations were identified.

Genetic dissection of yield into agronomic and physiological components

One approach for explaining yield through the genetic control of component traits is to consider genomic regions/ QTL associated with yield components starting with TGW

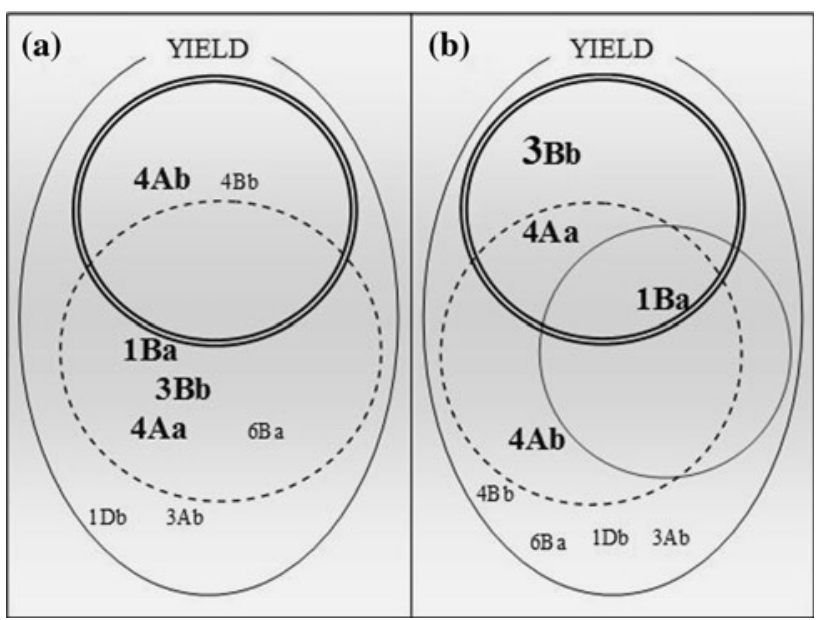

Fig. 6 Dissection of yield QTL into agronomy- and physiologyrelated QTL. a QTL for yield (single lined curve) dissected into QTL related to agronomic traits, QTL for $\mathrm{GM}^{-2}$ (dotted circle) QTL for TGW (double lined circle); b QTL for yield dissected into physiological traits, QTL for CT (double lined circle); QTL for NDVI (dotted circle); QTL for CHL(single lined curve); Big fonts are robust QTL for yield while small fonts are suggestive QTL for yield

and $\mathrm{GM}^{-2}$ (Fig. 6). A more complete arithmetic analysis would include all yield components, namely number of plants per unit area, number of spikes per plant, number of spikelets per spike, number of fertile florets, and grain weight. In general, grain yield can be assessed through the combination of two components: grain weight and grain number. A multiple linear regression model across environments showed that $66 \%$ of the yield variance was explained by TGW and $\mathrm{GM}^{-2}$ (data not shown), and QTL for diverse traits have been found to be co-located with yield QTL (Fig. 2). The genetic dissection of yield QTL with respect to yield components is expressed herein as a Venn diagram (Fig. 6). Of the four robust QTL for yield, three (1B-a, 3B-b, and 4A-a) were co-located with QTL for $\mathrm{GM}^{-2}$ and one (4A-b) with TGW (Fig. 6a). Similarly, with respect to physiological traits, the yield QTL were also colocated with QTL for the following physiological traits: CT (three QTL), NDVI (three QTL), and CHL (one QTL), while suggestive QTL for WSC were common to all four QTL (Fig. 6b).

\section{Discussion}

QTL mapping for agronomic and physiological performance traits

Although several physiological traits have been shown in wheat to be associated with genetic variation or improvement under drought (Olivares-Villegas et al. 2007; Richards 2006), relatively few QTL for physiological traits 
have been identified to date (Rebetzke et al. 2008a, b; Reynolds and Tuberosa 2008), fewer still have been utilized in breeding, and none have been cloned (Collins et al. 2008). Table 6 summarizes the results from 23 studies that have identified chromosomal regions in wheat associated with the expression of agronomic, and in a few cases, physiological traits. Results of the current study show broad agreement with these previous studies (shaded cells in Table 6) with the main difference being fewer co-locations with phenology-related QTL. While the nature of QTL mapping restricts the comparison of specific markers across populations, chromosomal regions are still indicative. For the Seri/Babax population all traits were controlled by multiple genomic regions (Figs. 3, 4, 5), especially under stress, highlighting the complex nature of the adaptation process. In this study, the most important chromosomal regions were 1B-a, 2B-a, 3B-b, 4A-a, 4A-b, and 5A-a (Table 4; Supplementary Fig. 1) which were associated with 10, 9, 8, 7, 7, and 7 traits, respectively.

In other populations, QTL on the short arm of chromosome $1 \mathrm{~B}$ have been related to performance traits such as those related to transpiration efficiency (Rebetzke et al. 2008a) and to yield (Marza et al. 2006). The increasing yield effects in this study associated with the short arm of chromosome $1 \mathrm{~B}$ were from the Babax parent, i.e. the allele from Seri associated with the T1BL.1RS (rye) translocation resulted in decreased yield. This effect was also reported by Mathews et al. (2008) for Australian drought and irrigated trials of the Seri/Babax population. In previous studies of isolines of Seri M82, the T1BL.1RS rye translocation was shown to increase yield by $11 \%$ under terminal stress (Villareal et al. 1998). The 1BL.1BS donor for the Villareal study was an older CIMMYT line, Pavon F76, which may well have had weaker alleles for yield on 1BS compared to those present in the Babax parent in this study. In common with Mathews et al. (2008), Peake (2003), examining a cross between Seri M82 and Hartog (a sister line of Pavon F76), also found no advantage of the T1BL.1RS rye translocation in Australian environments. The major use of the T1BL.1RS rye translocation has been to improve disease resistance although it has also frequently been reported to decrease grain quality, e.g. Gobaa et al. (2008). In conjunction with other reports such as Rebetzke et al. (2008a), it seems that there is alleleic variation in the effects of the $1 \mathrm{BS}$ chromosome segment, and that the impact on yield is not always inferior to that of $1 \mathrm{RS}$, at least in environments where the disease pressures are low.

The co-location of two or more QTL is indicative of pleiotropic or linkage effects (Huang et al. 2004), for example where yield QTL co-located with other QTL for $\mathrm{CTg}, \mathrm{CTV}$ and $\mathrm{GM}^{-2}$ on 3B-b. The 3B-b region was previously reported by Miura and Worland (1994) to affect vernalization, but in these relatively warm (spring wheat) environments it was not associated with any variation in flowering time (Table 1). The yield and CTV increments controlled on region $4 \mathrm{~A}-\mathrm{a}$ by contrasting alleles confirms their strong negative correlations (Olivares-Villegas et al. 2007) and suggests that cooler canopies, due to the absence of the Seri allele on the $4 \mathrm{~A}-\mathrm{a}$ region, would result in higher yields, especially under irrigated conditions exposed to continuous high aerial temperature. The robust QTL found on 4A-a (identified as the yield QTL of highest effect in Table 5) was previously reported by Kuchel et al. (2007) and Marza et al. (2006) as being related to yield, but those pedigrees were quite different to the Seri-Babax population (coefficient of parentage with Seri M 82 and Babax $<0.077$ ). This region has been identified as affecting a number of important traits, including yield, flowering time, amylase content, and grain weight (Araki et al. 1999; Kirigwi et al. 2007; McCartney et al. 2005). Coincident location of diverse QTL for yield, yield components, and some physiological traits in the 1B-a, 3B-b, 4A-a, and 4A-b (Table 4) suggest the possible existence of a group of genes involved in important mechanisms for performance of wheat under DRT (Kirigwi et al. 2007), as well as HOT, and IRR environments.

The repeatable QTL for $\mathrm{GM}^{-2}$ on 5B-a (Table 4) was also reported as co-locating with a yield QTL by Kuchel et al. (2007). Two robust QTL for TGW and height on 4B-b (Table 4) have been previously reported by McCartney et al. (2005) and Huang et al. (2004) in a similar region. These authors had suggested that this region may be associated with the Rht-BI gene, and later Marza et al. (2006) confirmed that the 4B QTL had a strong influence on height in his population. However, Seri and Babax do not segregate for any known Rht genes, and given their common pedigree likely share the same $R h t$ allele regardless.

Value of using progeny expressing a restricted range of phenology

Variation in wheat phenology is determined by genes of major effect (Ppd and Vrn), as well as minor effects associated with "Earliness per se" (Eps) (Worland 1996). Given that alleles for major Ppd and Vrn are known, their effects on drought adaptation can be studied relatively easily using near isogenic lines generated by backcrossing into any genetic backgrounds (Dyck et al. 2004). When studying minor genetic effects, a population should comprise individuals with synchronized phenological cycles, such that all lines will pass through the same developmental stages at the same time, and hence, assure that all the genotypes will experience the same environmental conditions in each stage. By avoiding segregation for genes of major phenology effects in mapping populations, the probability of identifying genes of minor effect (i.e. those affecting complex traits) is expected to 


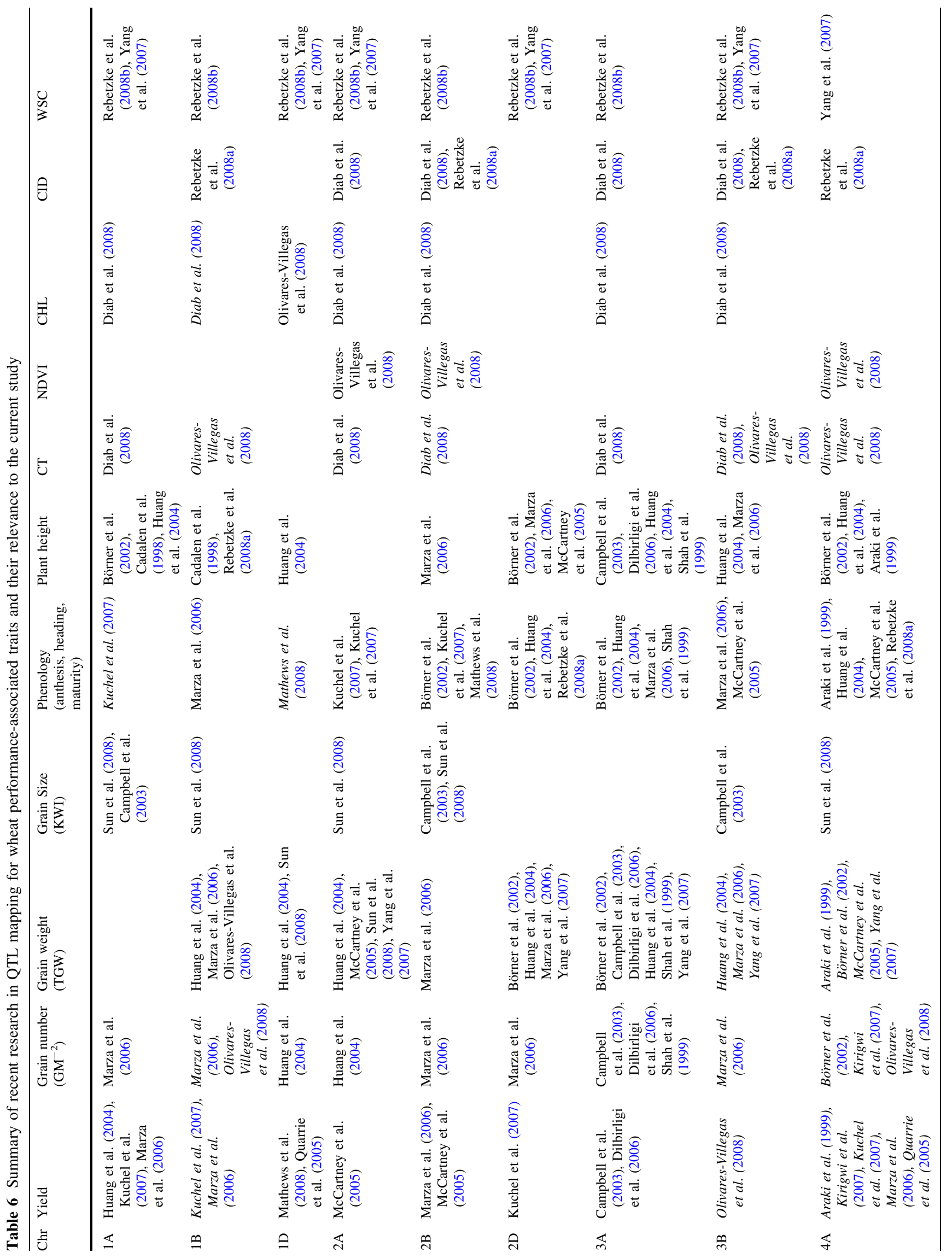




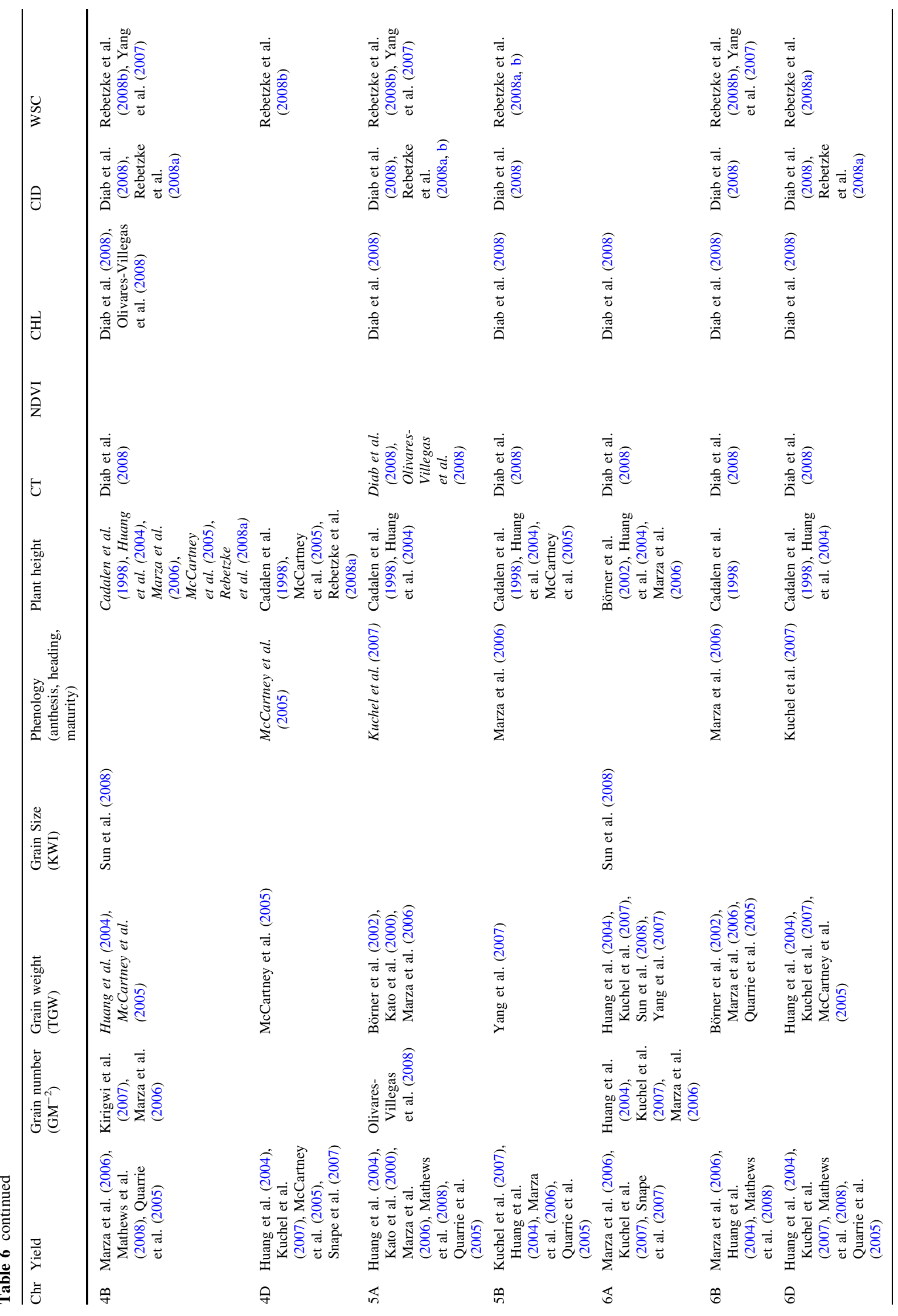




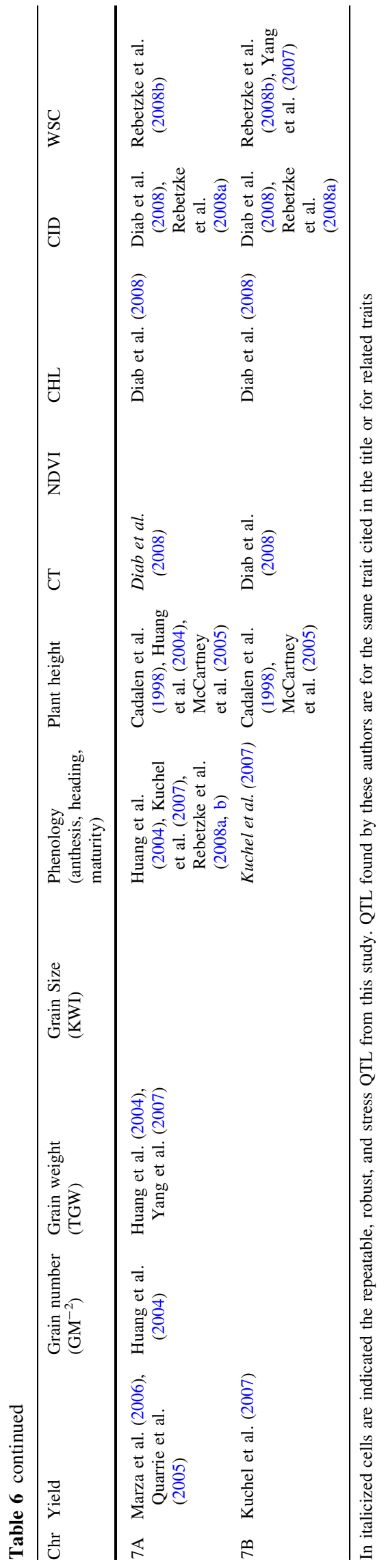

increase (Reynolds and Tuberosa 2008) as recently demonstrated by subdividing a large $\mathrm{DH}$ wheat mapping population (Kukri/RAC875) into early and late sub populations for QTL analysis (Reynolds et al. 2009). The relatively narrow range of phenology of the elite Seri/Babax population helps avoid confounding of environment patterns (Olivares-Villegas et al. 2007) as indicated by the following observations.

- In contrast to previously reported studies (Table 6), there were minimum coincidence of any repeatable, stress or robust QTL for yield, yield components, CHL, NDVI or WSC with phenology-related QTL (Table 4); many other studies found common regions for phenology and yield (Araki et al. 1999; Kirigwi et al. 2007; Kuchel et al. 2007; Marza et al. 2006; McCartney et al. 2005), CID (Rebetzke et al. 2008a), TGW (Börner et al. 2002; Huang et al. 2004), and $\mathrm{GM}^{-2}$ (Shah et al. 1999).

- In the current study, the HOT environments with the lowest variation in anthesis date also had more significant QTL effects for all physiological traits (yield, NDVI, WSC, CT, and CHL) compared with IRR environments which had greater variation in flowering time (Figs. 3, 5).

- Herein, a group of QTL "clusters" were clearly identified for physiological traits, i.e. CT, CHL, WSC, and NDVI, indicating the existence of consistent genomic regions that contain important groups of genes controlling or affecting their expression. The QTL appeared repeatedly across stressed and non-stressed environments at 1B-a, 2B-a, 3B-b, 4A-a, and 7A-a linkage groups.

The fact that most reported studies in wheat mapping populations do not even report phenological range, and in all cases where it is the range is relatively large, up to 3 weeks (Table 4), confirms that control of phenology is generally an experimental bottleneck to gene discovery for complex traits, such as those associated with drought and heat adaptation.

Common QTL associated with drought and heat adaptive traits

Different conditions induce gene expression at different loci, but some genomic regions may have value under multiple environments. QTL that are significant under different kinds of abiotic stress, such as those identified in common to both DRT and HOT environments in the current study (Fig. 2), could be useful in breeding for target environments that encompass a range of abiotic stresses. The overlapping of intervals for CTv and CTg further suggested that the ability to maintain low CT may be associated with the same genes at different growth stages as well as under different environments (Fig. 2); favorable expression of CT under drought is linked to increased root depth in drought adapted Seri/Babax 
sisters (Lopes and Reynolds 2010) while improved root capacity is also likely to permit a larger transpiration rate and therefore cooler CT under hot conditions. Other regions have suggested common drought and heat associated genes for anthesis (4D-a, 5A-a), maturity (5A-a, 7B-a), KWI (1A-a, 2B-a), and TGW (4A-a) (Table 4).

Genetic dissection of yield

Grain yield is an integrative trait including the net effect of all physiological processes during the crop cycle. However, significant interactions of yield and QTL effects with environment, especially under stress, make it difficult to use yield QTL directly in selection. The dissection of yield into associated traits could assist breeders to identify specific desirable characteristics with higher heritability and tagged by DNA markers for more reliable selection; cf. selection for yield per se. As shown in Fig. 6, all of the repeatable, robust, and stress QTL for yield were common to $\mathrm{GM}^{-2}$ or TGW QTL, while considering also the suggestive QTL, more than $50 \%$ of the QTL detected for yield were common to the yield components. Common genomic regions for yield and yield components have also been reported in previous studies, i.e. co-locations of QTL related to yield and QTL for grain weight (Araki et al. 1999; Kato et al. 2000; Marza et al. 2006; McCartney et al. 2005) and grain number (Campbell et al. 2003; Kirigwi et al. 2007). The co-location of QTL associated with different traits can be the result of: (1) Two strongly linked genes affecting different traits, (2) One single gene that produces a series of effects in related traits, (3) One gene affecting two or more independent traits, (4) Two linked genes with effects in the same traits (Yang et al. 2007). Groos et al. (2003) have suggested that QTL for traits like TGW could be successfully used for yield improvement due to its accurate detection and repeatability across environments in comparison to the QTL for yield, and it could be complemented by adding correlated grain number QTL. However, in practice, this could be difficult to achieve to the extent that grain number and potential grain size could be affected by competing mechanisms during early stages of ovule and grain development. In this study, $\mathrm{GM}^{-2}$ and TGW showed five and three repeatable, robust or stress QTL, respectively (which could therefore be selected for), in comparison to yield which showed four QTL.

Physiological dissection showed that all of the four yield QTL were accounted by CT, NDVI, CHL, and WSC together, the first three being traits that may be more closely associated with biomass production per se (via maintenance of transpiration and leaf nitrogen content) rather than grain set processes. In contrast to yield QTL, selection for the respective QTL associated with physiological traits can be guided by conceptual models of trait expression, in accordance with the specific characteristics of the target environments (Reynolds et al. 2007). For example, QTL for cooler canopies associated with access to water at deeper soil profiles, (Lopes and Reynolds 2010) would only be a priority for target environments with suitable soil characteristics and QTL associated with high ground cover (NDVI) may not be needed in farming systems where soil cover is achieved through crop residue retention and/or crops that rely on stored soil water.

\section{Conclusions}

This population did not segregate for major flowering time genes, with a consequent restriction of phenology. Unlike most other similar studies, QTL for anthesis were generally not co-located with performance QTL. Furthermore, QTL were identified that explained up to $27 \%$ variation in yield and $28 \%$ variation in canopy temperature, independently of confounding effects of phenology.

Common genomic regions for drought and heat suggest a generic value across stresses for several of the QTL identified. Chlorophyll (CHLg), NDVI, and canopy temperature (CT) are examples of traits previously reported as being related to yield under both drought and heat. According to the results presented here, their genetic basis may be associated with the same genomic regions and controlled by the same parent allele irrespective of the environment.

The co-location of QTL for diverse agronomic and physiological traits with QTL for yield directly support the genetic dissection of the crop performance in order to facilitate a more strategic approach to breeding for adaptation. Those regions identified across environments are candidates that can be used in MAS or gene cloning, especially if they show moderate to high broad sense heritabilities.

Acknowledgments The authors acknowledge support from the Grains Research and Development Corporation (GRDC project CSP00053 for R. Suzuky Pinto); the CRC for Molecular Plant Breeding (scholarship for Juan Jose Olivares-Villegas), the Generation Challenge Program (support for Ky Mathews) and the United States Agency for International Development (USAID). We are very grateful to Dan Mullan and Marta Lopes for their critical advice and to Eugenio Pérez and Israel Peraza for their invaluable technical and field assistance.

Open Access This article is distributed under the terms of the Creative Commons Attribution Noncommercial License which permits any noncommercial use, distribution, and reproduction in any medium, provided the original author(s) and source are credited.

\section{References}

Araki E, Miura H, Sawada S (1999) Identification of genetic loci affecting amylose content and agronomic traits on chromosome 4A of wheat. Theor Appl Genet 98:977-984 
Araus JL, Slafer GA, Royo C, Serret MD (2008) Breeding for yield potential and stress. Adaptation in cereals. Crit Rev Plant Sci 27:377-412

Börner A, Schumann E, Fürste A, Cöster H, Leithold B, Röder MS, Weber WE (2002) Mapping of quantitative trait loci determining agronomic important characters in hexaploid wheat (Triticum aestivum L.). Theor Appl Genet 105:921-936

Breseghello F, Sorrells ME (2007) QTL analysis of kernel size and shape in two hexaploid wheat mapping populations. Field Crops Res 101:172-179

Cadalen T, Sourdille P, Charmet G, Tixier MH, Gay G, Boeuf C, Bernard S, Leroy P, Bernard M (1998) Molecular markers linked to genes affecting plant height in wheat using a doubled-haploid population. Theor Appl Genet 96:933-940

Campbell BT, Baenziger PS, Gill KS, Eskridge KM, Budak H, Erayman M, Dweikat I, Yen Y (2003) Identification of QTLs and environmental interactions associated with agronomic traits on chromosome 3A of wheat. Crop Sci 43:1493-1505

Collins NC, Tardieu F, Tuberosa R (2008) Quantitative trait loci and crop performance under abiotic stress: where do we stand? Plant Physiol 147:469-486

Comadran J, Russell JR, van Eeuwijk FA, Ceccarelli S, Grando S, Baum M, Stanca AM, Pecchioni N, Mastrangelo AM, Akar T, Al-Yassin A, Benbelkacem A, Choumane W, Ouabbou H, Dahan R, Bort J, Araus JL, Pswarayi A, Romagosa I, Hackett CA, Thomas WTB (2008) Mapping adaptation of barley to droughted environments. Euphytica 161:35-45

Condon AG, Richards RA, Rebetzke GJ, Farquhar GD (2004) Breeding for high water-use efficiency. J Exp Bot 55:2447-2460

Cullis BR, Smith AB, Coombes NE (2006) On the design of early generation variety trials with correlated data. J Agric Biol Environ Stat 11:381-393

Diab AA, Kantety RV, Ozturk NZ, Benscher D, Nachit MM, Sorrells ME (2008) Drought-inducible genes and differentially expressed sequence tags associated with components of drought tolerance in durum wheat. Sci Res Essay 3:009-026

Dilbirligi M, Erayman M, Campbell BT, Randhawa HS, Baenziger PS, Dweikat I, Gill KS (2006) High-density mapping and comparative analysis of agronomically important traits on wheat chromosome 3A. Genomics 88:74-87

Dyck JA, Matus-Cádiz MA, Hucl P, Talbert L, Hunt T, Dubuc JP, Nass H, Clayton G, Dobb J, Quick J (2004) Agronomic performance of hard red spring wheat isolines sensitive and insensitive to photoperiod. Crop Sci 44:1976-1981

Eathington SR, Crosbie TM, Edwards MD, Reiter RS, Bull JK (2007) Molecular markers in a commercial breeding program. Crop Sci 47:154-163

Falconer DS (1981) Introduction to quantitative genetics, 2nd edn. Longman, New York

Gilmour AR, Cullis BR, Verbyla AP (1997) Accounting for natural and extraneous variation in the analysis of field experiments. J Agric Biol Environ Stat 2:269-293

Gobaa S, Brabant C, Kleijer G, Stamp P (2008) Effect of the 1BL.1RS translocation and of the Glu-B3 variation on fifteen quality tests in a doubled haploid population of wheat (Triticum aestivum L.). J Cereal Sci 48:598-603

Groos C, Robert N, Bervas E, Charmet G (2003) Genetic analysis of grain protein-content, grain yield and thousand-kernel weight in bread wheat. Theor Appl Genet 106:1032-1040

Holland JB (2006) Estimating genotypic correlations and their standard errors using multivariate restricted maximum likelihood estimation with SAS Proc MIXED. Crop Sci 46:642-654

Huang XQ, Kempf H, Ganal MW, Röder MS (2004) Advanced backcross QTL analysis in progenies derived from a cross between a German elite winter wheat variety and a synthetic wheat (Triticum aestivum L.). Theor Appl Genet 109:933-943
Kato K, Miura H, Sawada S (2000) Mapping QTLs controlling grain yield and its components on chromosome 5A of wheat. Theor Appl Genet 101:1114-1121

Kirigwi FM, Van Ginkel M, Brown-Guedira G, Gill BS, Paulsen GM, Fritz AK (2007) Markers associated with a QTL for grain yield in wheat under drought. Mol Breed 20:401-413

Kuchel H, Williams KJ, Langridge P, Eagles HA, Jefferies SP (2007) Genetic dissection of grain yield in bread wheat. I. QTL analysis. Theor Appl Genet 115:1029-1041

Lantican MA, Pingali PL, Rajaram S (2003) Is research on marginal lands catching up? The case of unfavourable wheat growing environments. Agric Econ 29:353-361

Lopes MS, Reynolds MP (2010) Partitioning of assimilates to deeper roots is associated with cooler canopies and increased yield under drought in wheat. Funct Plant Biol 37:147-156

Ludlow MM, Muchow RC (1990) A critical evaluation of traits for improving crop yields in water-limited environments. Adv Agron 43:107-153

Marti J, Bort J, Slafer GA, Araus JL (2007) Can wheat yield be assessed by early measurements of normalized difference vegetation index? Ann Appl Biol 150:253-257

Marza F, Bai G-H, Carver BF, Zhou W-C (2006) Quantitative trait loci for yield and related traits in the wheat population Ning7840 × Clark. Theor Appl Genet 112:688-698

Mathews KL, Malosetti M, Chapman S, McIntyre L, Reynolds M, Shorter R, van Eeuwijk F (2008) Multi-environment QTL mixed models for drought stress adaptation in wheat. Theor Appl Genet 117:1077-1091

McCartney CA, Somers DJ, Humphreys DG, Lukow O, Ames N, Noll J, Cloutier S, McCallum BD (2005) Mapping quantitative trait loci controlling agronomic traits in the spring wheat cross RL4452 × 'AC Domain'. Genome 48:870-883

McIntyre CL, Mathews KL, Rattey A, Drenth J, Ghaderi M, Reynolds M, Chapman SC, Shorter R (2010) Molecular detection of genomic regions associated with grain yield and yield components in an elite bread wheat cross evaluated under irrigated and rainfed conditions. Theor Appl Genet 120(3):527-541

Miura H, Worland AJ (1994) Genetic control of vernalization, daylength response and earliness per se by homeologous group 3 chromosomes in wheat. Plant Breed 113:160-169

Montes JM, Melchinger AE, Reif JC (2007) Novel throughput phenotyping platforms in plant genetic studies. Trends Plant Sci 12:433-436

Oakey H, Verbyla A, Pitchford W, Cullis B, Kuchel H (2006) Joint modeling of additive and non-additive genetic line effects in single field trials. Theor Appl Genet 113:809-819

Olivares-Villegas JJ, Reynolds MP, McDonald GK (2007) Droughtadaptive attributes in the Seri/Babax hexaploid wheat population. Funct Plant Biol 34:189-203

Olivares-Villegas JJ, Reynolds MP, William HM, McDonald GK, Ribaut JM (2008) Drought adaptation attributes and associated molecular markers via BSA in the Seri/Babax hexaploid wheat (Triticum aestivum L.) population. In: Proceedings of the 11th international wheat genetics symposium, Brisbane, Australia, 24-29 Aug 2008. University Press, Sydney

Peake A (2003) Inheritance of grain yield and effect of the 1BL/1RS translocation in three bi-parental wheat (Triticum aestivum L.) populations in production environments of north eastern Australia. School of Land and Food Sciences, The University of Queensland, Brisbane

Quarrie SA, Steed A, Calestani C, Semikhodskii A, Lebreton C, Chinoy C, Steele N, Pljevljakusić D, Waterman E, Weyen J, Schondelmaier J, Habash DZ, Farmer P, Saker L, Clarkson DT, Abugalieva A, Yessimbekova M, Turuspekov Y, Abugalieva S, Tuberosa R, Sanguineti M-C, Hollington PA, Aragués R, Royo A, Dodig D (2005) High-density genetic map of hexaploid wheat 
(Triticum aestivum L.) from the cross Chinese Spring $\times$ SQ1 and its use to compare QTLs for grain yield across a range of environments. Theor Appl Genet 110:865-880

Rebetzke GJ, Condon AG, Farquhar GD, Appels R, Richards RA (2008a) Quantitative trait loci for carbon isotope discrimination are repeatable across environments and wheat mapping populations. Theor Appl Genet 118:123-137

Rebetzke GJ, van Herwaarden AF, Jenkins C, Weiss M, Lewis D, Ruuska S, Tabe L, Fettell NA, Richards RA (2008b) Quantitative trait loci for water-soluble carbohydrates and associations with agronomic traits in wheat. Aust J Agric Res 59:891-905

Reynolds M, Tuberosa R (2008) Translational research impacting on crop productivity in drought-prone environments. Curr Opin Plant Biol 11:171-179

Reynolds MP, Saint Pierre C, Saad ASI, Vargas M, Condon AG (2007) Evaluating potential genetic gains in wheat associated with stress-adaptive trait expression in elite genetic resources under drought and heat stress. Crop Sci 47:172-189

Reynolds MP, Manes Y, Izanloo A, Langridge P (2009) Phenotyping for physiological breeding and gene discovery in wheat. Ann Appl Biol 155:309-320

Richards RA (2006) Physiological traits used in the breeding of new cultivars for water-scarce environments. 2004 "New directions for a diverse planet". In: Proceedings of the 4th international crop science congress, 26 Sep-1 Oct 2004, Brisbane, Australia. Published on CDROM. http://www.cropscience.org.au

Ruuska SA, Rebetzke GJ, van Herwaarden AF, Richards RA, Fettell NA, Tabe L, Jenkins CLD (2006) Genotypic variation in watersoluble carbohydrate accumulation in wheat. Funct Plant Biol 33:799-809

Shah MM, Gill KS, Baenziger PS, Yen Y, Kaeppler SM, Ariyarathne HM (1999) Molecular mapping of loci for agronomic traits on chromosome 3A of bread wheat. Crop Sci 39:1728-1732
Smith A, Cullis BR, Gilmour A (2001) The analysis of crop variety evaluation data in Australia. Aust N Z J Stat 43:129-145

Snape JW, Foulkes J, Simmonds J, Leverington M, Fish LJ, Wang Y, Ciavarrella M (2007) Dissecting gene $\times$ environmental effects on wheat yields via QTL and physiological analysis. Euphytica 154:401-408

Sun X-Y, Wu K, Zhao Y, Kong F-M, Han G-Z, Jiang H-M, Huang X-J, Li R-J, Wang H-G, Li S-S (2008) QTL analysis of kernel shape and weight using recombinant inbred lines in wheat. Euphytica 165:615-624

Talamè V, Sanguineti MC, Chiapparino E, Bahri H, Ben Salem M, Forster BP, Ellis RP, Rhouma S, Zoumarou W, Waugh R et al (2004) Identification of Hordeum spontaneum QTL alleles improving field performance of barley grown under rainfed conditions. Ann Appl Biol 144:309-319

Tao YZ, Henzell RG, Jordan DR, Butler DG, Kelly AM, McIntyre CL (2000) Identification of genomic regions associated with stay green in sorghum by testing RILs in multiple environments. Theor Appl Genet 100:1225-1232

Villareal RL, Banuelos O, Mujeeb-Kazi A, Rajaram S (1998) Agronomic performance of chromosomes 1B and T1BL.1RS near-isolines in the spring bread wheat Seri M82. Euphytica 103:195-202

Wang S, Basten CJ, Zeng Z-B (2007) Windows QTL Cartographer 2.5. Department of Statistics, North Carolina State University, Raleigh, NC. (http://statgen.ncsu.edu/qtlcart/WQTLCart.htm)

Worland AJ (1996) The influence of flowering time genes on environmental adaptability in European wheats. Euphytica 89:49-57

Yang D-L, Jing R-L, Chang X-P, Li W (2007) Identification of quantitative trait loci and environmental interactions for accumulation and remobilization of water-soluble carbohydrates in wheat (Triticum aestivum L.) stems. Genetics 176:571-584 